\title{
A Simple Flexible and Robust Control Strategy for Wind Energy Conversion Systems Connected to a Utility Grid
}

\author{
Armel Simo Fotso $\mathbb{D}^{1,2}$ Godpromesse Kenné $\mathbb{D}^{1},{ }^{1}$ and Rostand Marc Douanla ${ }^{1,2}$ \\ ${ }^{1}$ Unité de Recherche d'Automatique et d'Informatique Appliquée (LAIA), Département de Génie Électrique, \\ IUT FOTSO Victor Bandjoun, Université de Dschang, BP 134 Bandjoun, Cameroon \\ ${ }^{2}$ Unité de Recherche de Matière Condensée d'Électronique et de Traitement du Signal (LAMACETS), \\ Département de Physique, Université de Dschang, BP 69 Dschang, Cameroon \\ Correspondence should be addressed to Armel Simo Fotso; fotsimmo@yahoo.fr
}

Received 10 January 2019; Revised 11 April 2019; Accepted 17 April 2019; Published 14 May 2019

Academic Editor: Haiping Du

Copyright ( 2019 Armel Simo Fotso et al. This is an open access article distributed under the Creative Commons Attribution License, which permits unrestricted use, distribution, and reproduction in any medium, provided the original work is properly cited.

\begin{abstract}
This paper presents a simple and robust control strategy for a variable speed wind turbine conversion system using a squirrel-cage induction generator and a three-phase voltage source (AC/DC/AC) Pulse Width Modulation (PWM) converter connected to the utility grid through an LCL filter. The control strategy integrates for the generator side an adaptive radial basis function (RBF) neurosliding mode controller associated with the rotor flux oriented vector control which is used to regulate the turbine rotation speed, rotor flux, and the DC bus voltage. For the grid side, the inverter current and voltage regulation as well as the current injected into the grid are regulated by PI controllers for two modes of operation, namely, the stand-alone mode and grid connected mode. The main contribution of this article is the introduction of a new and simple control algorithm allowing automatic mode switching method based on wind speed. The proposed scheme is very efficient and can be easily implemented in practice. Simulation results illustrate the effectiveness and feasibility of the proposed algorithm.
\end{abstract}

\section{Introduction}

1.1. Antecedents and Motivations. Wind energy conversion systems connected to the utility grid are becoming more rampant in recent years as the world's electricity power demand is growing. Several studies have demonstrated that the installed wind power generation capacity in the world has been increasing at more than $30 \%$ per year for the last 10 years [1]. The major advantage of these systems is the abundant availability of the wind power source as compared to conventional energy sources such as natural gas, oil, etc. To improve their efficiency, an adequate choice of electrical generator together with an advanced and reliable control strategy is needed.

Among the different variants of electrical generators, the squirrel-cage induction machine is one of the best candidates for the implementation of the variable wind speed conversion system in both isolated and grid connected production due to its numerous advantages such as its robustness and reduced price which considerably decreases the cost of installation of the wind conversion system as well as the price of the energy produced. The disadvantages of this machine are, among others, the very high coupling which exists between its parameters and which induces a poor regulation of voltage and frequency as well as the necessity for an external excitation source.

Variable speed operation of wind turbines has many advantages that are well known in the literature, but simple and reliable control methods under wind speed variation need to be developed in order to improve the performances of the wind energy conversion system in both grid connected and stand-alone operating modes. For the grid connected mode, the power produced by the wind turbine needs to be regulated in order to be injected into the grid. Furthermore, the injected voltage has to be synchronized with the grid voltage. Thus to achieve these objectives, a power converter which enables a certain controllability of electrical power in the grid is needed. To achieve grid synchronization, different 
methods to extract the phase angle have been studied in the literature such as zero crossing method, filtering of grid voltage method, and PLL technique [2]. However, the PLL technique is the most used method for grid synchronization due to its numerous advantages such as better rejection of grid harmonics and others kind of disturbances.

In recent years, some advanced control strategies have been proposed for wind energy conversion systems [3-11]. In [3], the authors examined the voltage regulation at the load terminal through the control of a single-phase PWM inverter. The proposed algorithm ensures a perfect switching between the two operation modes and provides an uninterrupted power supply to the load. However, the study concerns only a single-phase system. A distributed generation unit connected to the grid using a variable speed permanent magnet synchronous generator is examined in [4]. The proposed control scheme ensures good DC-link regulation, low distortion, and high quality power flows into the grid. However, time-varying parameter estimation and flexible control between grid connected and stand-alone operation modes have not been investigated. In [5], a control algorithm for a wind conversion system based on a permanent magnet synchronous generator for an isolated site is presented. A first-order sliding mode control technique is developed for the control of the generator side quantities as well as the extraction of the maximum available power on the wind turbine. Nevertheless, the grid connected mode has not been investigated. A grid connected wind conversion system based on a squirrel-cage induction generator is examined in [6]. In this paper, an adaptive control algorithm based on PI controllers for a three-phase rectifier ensures the regulation of the generator side quantities. A three-phase PWM controlled inverter connected to the grid through an LCL filter regulates the voltage across the load and the grid current. However, the authors did not address the problem of power drop detection. In [10], the authors designed a RBF neurosliding mode controller for a stand-alone variable wind speed conversion system. But the grid connected mode operation has not been investigated. A robust control algorithm for a three-phase voltage source inverter directly connected to the grid through an LCL filter is presented in [7]. But only the current injected to the network is regulated to stabilize the system. Reference [9] presents the modelling of a PV module and a new control topology for a single stage three-phase grid connected photovoltaic system. The controls aims include simultaneously grid synchronization, reactive power compensation, output current harmonic reduction, and maximum power point tracking. Nevertheless flexible control between standalone mode operation and grid connected mode operation has not been investigated. In [12], the authors examined a variable speed generation system which contains a voltage source inverter connected to the grid through an LCL filter with the MPPT algorithm and unity power factor. However, the configuration offers a weak harmonic performance at lower switching frequencies in higher power applications. In addition, the uninterruptible supply of the ACload during the transition between grid connected and stand-alone modes has not been investigated. A flexible algorithm for the control of a small wind conversion system with grid failure detection and automatic switching between the grid connected and stand-alone operating modes based on a PLL controller is proposed in [8]. But details on the generator side control such as flux and generator speed regulation have not been provided. Furthermore the variation of electrical parameters has not been investigated.

From this review it can be noticed that concerning the wind energy conversion systems authors have not yet investigated the method which consists in effectively transferring the maximum power captured by the wind turbine to the grid. It is also noteworthy that a flexible control of wind energy conversion system, with power detection, operating in standalone and grid connected mode has not yet been investigated.

1.2. Main Contribution. From the above drawbacks, we propose in this paper, a complete wind turbine conversion system based on a squirrel-cage induction machine connected to the utility grid through an LCL filter. A rotor flux oriented vector control strategy associated with a RBF neurosliding mode control technique is used to regulate the DC bus voltage, the rotor flux, and the rotating speed of the generator under a large variation of the wind turbine speed. The control of the grid side PWM converter is ensured by a simple, flexible, and robust algorithm enabling:

(i) The automatic switch between two functioning mode based on wind speed.

(ii) The voltage regulation across the load.

(iii) The grid current regulation.

In order to ensure an optimal operation of the proposed conversion system, a control method based on the MPPT technique is proposed. It consists in effectively transferring the maximum power extracted by the wind turbine for each wind speed to the grid. A three-phase voltage source $\mathrm{AC} / \mathrm{DC} / \mathrm{AC}$ converter associated with a flux oriented vector control of the self-excited induction generator (SEIG) is used. The algorithm integrates the regulation of the rotor flux and generator rotor speed as well as the DC bus voltage control to improve the efficiency of the overall system. The low speed operation of the system implies that it can be operated in isolated areas with weak wind profile.

1.3. Structure of the Paper. The paper is organized as follows: In Section 2, the RBF neural network controller is designed. In Section 3, the nonlinear dynamics of induction generator and control objectives are introduced and the RBF neurosliding mode control technique is designed to achieve the regulation of DC bus voltage, rotor flux, and generator speed with adaptation of rotor time constant. In Section 4, the PI control strategy is developed for grid side inverter. In Section 5, computing results using the proposed RBF neurosliding mode technique and PI controllers, respectively, for generator and grid side are reported. Some concluding remarks are given in Section 6. 


\section{Design of RBF Neural Network Controller}

In this section, a direct method for robust adaptive control using RBF neural network for a class of nonlinear systems is propose. form:

Let us consider the nonlinear system in the following

$$
\begin{aligned}
\dot{x}_{1} & =x_{2} \\
\dot{x}_{2} & =f(x, t)+g(x, t) z+d(t) \\
y & =x_{1}
\end{aligned}
$$

where $x=\left(x_{1}, x_{2}\right)^{T} \in R^{2}, z \in R$, and $y \in R$, are, respectively, state variables, system input, and output; $f(x, t)$ and $g(x, t)$ are unknown smooth functions; $f(x, t)$ is the nominal part of the system; it does not depend upon the control input while the uncertainties and external disturbance are concentrated in the term $d(t)$ assumed to be bounded by an unknown constant $d_{0}>0$. Since all physical plants operate in bounded regions, we study the control problem of system (1) whose state $x$ belongs to a compact subset $\Omega \subset R^{2}$.

Assumption 1. The sign of $g(x, t)$ is known and $g(x, t) \neq$ $0 \forall x \in \Omega$. Since the sign of $g(x, t)$ is assumed to be known, without losing generality, we may assume that $g(x, t)>$ $0 \forall x \in \Omega$ in the following development. The case where $g(x, t)<0$ is discussed in Remark.

Assumption 2. It is also assume that $\dot{g}(x, t) \leq 0$.

Remark 3. Assumption 1 seems to be a restriction for the proposed control scheme. It should be noticed that many physical electromechanical systems [13-16] possess such a property.

Assumption 2 is not a restriction for the proposed control scheme. It has been used to simplify the study in this section. The case when the sign of $\dot{g}(x, t)$ is not constant will be discussed later.

Define the desired smooth signal $y^{*}=x_{1}^{*}$, the tracking error $e_{x}$, and augmented item $S_{x}$, as

$$
\begin{aligned}
& e_{x}=x_{1}-x_{1}^{*}, \\
& S_{x}=l_{x} e_{x}+\dot{e}_{x}
\end{aligned}
$$

where $l_{x}>0$ is a design parameter. From (2), we have

$$
\begin{aligned}
\dot{S}_{x} & =l_{x} \dot{e}_{x}+\ddot{e}_{x}=l_{x} \dot{e}_{x}+\dot{x}_{2}-\ddot{x}_{1}^{*} \\
& =l_{x} \dot{e}_{x}+f(x, t)+g(x, t) z+d(t)-\ddot{x}_{1}^{*} \\
& =f(x, t)+g(x, t) z+\mu_{x}+d(t) \\
& \quad \text { with } \mu_{x}=l_{x} \dot{e}_{x}-\ddot{x}_{1}^{*} .
\end{aligned}
$$

Proposition 4. Consider system (1). If the desired controller is chosen as

$$
z_{x}^{*}=-\frac{1}{g(x, t)}\left(f(x, t)+\mu_{x}+d(t)\right)-\frac{S_{x}}{\varepsilon_{x}}
$$

where $0<\varepsilon_{x}<1$ is a design parameter, then $S_{x}$ converges exponentially to 0 .

Proof. Substituting $z_{x}^{*}$ into (3) yields

$$
\dot{S}_{x}=-\frac{S_{x}}{\varepsilon_{x}} .
$$

Remark 5. The above desired controller $z_{x}^{*}$ is not implementable since the functions $f(x, t), g(x, t)$ and the terms $\mu_{x}$ and $d(t)$ are assumed to be unknown. In the following, RBF neural network combined with the sliding mode technique will be applied to approximate the unknown controller $z_{x}^{*}$.

From (4), the desired controller $z_{x}^{*}$ can be rewritten as

$$
\begin{aligned}
& z_{x}^{*}\left(\chi_{x}, t\right)=z_{x_{n}}^{*}\left(\chi_{x}\right)+\delta_{z_{x}}(t) \\
& \text { with } \chi_{x}^{T}=\left(x_{1}, S_{x}, \frac{S_{x}}{\varepsilon_{x}}\right) \in \Omega_{x}
\end{aligned}
$$

where the first term $z_{x_{n}}^{*}$, function of $x_{1}, S_{x}$, and $S_{x} / \varepsilon_{x}$, is the nominal continuous bounded part, the second term $\delta_{z_{x}}(t)$ is the uncertain part assumed to be bounded by unknown constant, and compact set $\Omega_{x}$ is defined as

$$
\begin{aligned}
\Omega_{x} & =\left\{\left(x_{1}, S_{x}, \frac{S_{x}}{\varepsilon_{x}}\right) \mid x_{1} \in R, x_{1}^{*} \in R, e_{x}=x_{1}\right. \\
& \left.-x_{1}^{*}, S_{x}=l_{x} e_{x}+\dot{e}_{x}\right\} .
\end{aligned}
$$

The nominal part of the above controller is continuous and can be approximated by a radial basis function (RBF) neural network [17, 18]. Thus, $z_{x}^{*}$ can be described as follows [19]:

$$
\begin{aligned}
z_{x}^{*}\left(\chi_{x}, t\right)= & \Psi\left(\chi_{x}, w^{*}\right)+e_{f}\left(\chi_{x}\right)+\delta_{z_{x}}(t) \\
& \text { with } \Psi\left(\chi_{x}, w^{*}\right)=\sum_{j=1}^{N} w_{j}^{*} \phi\left(\left\|\chi_{x}-C_{j}\right\|, v_{j}\right),
\end{aligned}
$$

where $\phi(\cdot)$ denotes a nonlinear function; $C_{j}$ and $v_{j}, j=$ $1, \ldots, N$ are the center and the width of the $j$-th hidden unit, respectively; $N$ is the number of the hidden nodes or radial basis function units (RBF); $w^{*}$ is the optimal weight vector and satisfies $\left\|w^{*}\right\| \leq R_{\omega} ; \chi_{x}^{T}=\left(x_{1}, S_{x}, S_{x} / \varepsilon_{x}\right)$ is the input vector of the RBF network; $e_{f}\left(\chi_{x}\right)$ is the optimal approximation error, which is unknown and bounded $\forall \chi_{x} \epsilon$ $\Omega_{\mathrm{x}}$.

Note that the term $\delta_{z_{x}}(t)$ is time-varying and cannot be approximated by a static neural network. In the following analysis, sliding robust terms will be used in the identification scheme to compensate the effect of this uncertainty timevarying term. The controller $z_{x_{1}}^{*}\left(\chi_{x}, t\right)$ will be approximated assuming that the terms $\delta_{z_{x}}(t)$ and $e_{f}\left(\chi_{x}\right)$ are bounded by unknown positive constants.

For this purpose, the following neural controller is proposed in order to approximate the control signal $u_{x}^{*}\left(\chi_{x}, t\right)$

$$
\widehat{z}_{x}^{*}\left(\chi_{x}, t\right)=\Psi\left(\chi_{x}, \widehat{w}\right)+b_{x}(t)
$$


where the term $b_{x}(t)$ is introduced in order to improve the convergence rate of the neural network in the presence of the uncertainties terms.

Substituting (9) in (3) yields

$$
\begin{aligned}
\dot{S}_{x}= & f(x, t)+g(x, t)\left[\Psi\left(\chi_{x}, \widehat{w}\right)+b_{x}(t)\right]+\mu_{x} \\
& +d(t) \\
= & f(x, t)+g(x, t)\left[\Psi\left(\chi_{x}, \widehat{w}\right)-\Psi\left(\chi_{x}, w^{*}\right)\right] \\
& -g(x, t)\left[e_{f}\left(\chi_{x}\right)+\delta_{z_{x}}(t)\right]+g(x, t) z_{x}^{*}\left(\chi_{x}, t\right) \\
& +g(x, t) b_{x}(t)+\mu_{x}+d(t) .
\end{aligned}
$$

From (4), we have

$$
g(x, t) z_{x}^{*}\left(\chi_{x}, t\right)=-f(x, t)-\mu_{x}-d(t)-g(x, t) \frac{S_{x}}{\varepsilon_{x}}
$$

Substituting (11) in (10) yields

$$
\begin{aligned}
\dot{S}_{x}= & g(x, t)\left[\Psi\left(\chi_{x}, \widehat{w}\right)-\Psi\left(\chi_{x}, w^{*}\right)\right] \\
& -g(x, t)\left(e_{f}\left(\chi_{x}\right)+\delta_{z_{x}}(t)\right)+g(x, t) b_{x}(t) \\
& -g(x, t) \frac{S_{x}}{\varepsilon_{x}} .
\end{aligned}
$$

From the fact that the neural network is a linear function of $\widehat{w}$ and using Taylor series expansion, (12) can be rewritten as

$$
\begin{aligned}
\dot{S}_{x}= & g(x, t) b_{x}(t)+\left.g(x, t) \sum_{j=1}^{N} \frac{\partial \Psi}{\partial w_{j}}\right|_{w=\widehat{w}_{j}}\left(\widehat{w}_{j}-w_{j}^{*}\right) \\
& -g(x, t)\left[e_{f}\left(\chi_{x}\right)+\delta_{z_{x}}(t)\right]-g(x, t) \frac{S_{x}}{\varepsilon_{x}}
\end{aligned}
$$

where $e_{f}\left(\chi_{x}\right)$ and $\delta_{z_{x}}(t)$ are assumed to be bounded as follows

$$
\left|e_{f}\left(\chi_{x}\right)+\delta_{z_{x}}(t)\right| \leq \lambda_{x},
$$

and $\lambda_{x}$ is unknown positive constant.

Proposition 6. Consider the class of nonlinear systems described by (1), the sliding-neural network controller (9), and Assumptions 1 and 2. If the bias term $b_{x}(t)$, the learning rule of the weight $w$, and the adaptation law for the unknown bound $\lambda_{x}$ are chosen as

$$
\begin{aligned}
b_{x}(t) & =-\widehat{\lambda}_{x} \operatorname{sgn}\left(S_{x}\right) \\
\dot{\widehat{w}}_{j} & =\operatorname{Proj}\left[-\left.S_{x} \frac{\partial \Psi}{\partial w_{j}}\right|_{w_{j}=\widehat{w}_{j}}\right], \quad j=1, \ldots, N \\
& = \begin{cases}-\left.S_{x} \frac{\partial \Psi}{\partial w_{j}}\right|_{w_{j}=\widehat{w}_{j}} & \text { if }\left|\widehat{w}_{j}\right|<R_{w} \\
0 & \text { otherwise }\end{cases} \\
\dot{\hat{\lambda}}_{x} & = \begin{cases}\alpha_{x} & \text { if } S_{x} \neq 0 \\
0 & \text { if } S_{x}=0,\end{cases}
\end{aligned}
$$

with $\alpha_{x}>0, \hat{\lambda}_{x}(0)=0$, and $\operatorname{Proj}(\cdot)$ being the well-known projection function [20] on the compact set $\Omega_{\omega}=\{\omega:\|\omega\| \leq$ $\left.R_{\omega}\right\}$, then the neural network controller error $S_{x}$ will converge in finite time to the origin.

Proof. In order to prove the finite time convergence to the origin of neural network controller error $S_{x}$, the following Lyapunov candidate function is considered:

$$
\mathrm{V}=\frac{1}{2} S_{x}^{2}+\frac{1}{2} g(x, t) \sum_{j=1}^{N}\left(\widehat{w}_{j}-w_{j}^{*}\right)^{2}
$$

Computing its time-derivative yields

$$
\begin{aligned}
\dot{\mathrm{V}}= & S_{x} \dot{S}_{x}+g(x, t) \sum_{j=1}^{N} \dot{\widehat{w}}_{j}\left(\widehat{w}_{j}-w_{j}^{*}\right) \\
& +\frac{1}{2} \dot{g}(x, t) \sum_{j=1}^{N}\left(\widehat{w}_{j}-w_{j}^{*}\right)^{2} .
\end{aligned}
$$

Considering (13) yields

$$
\begin{aligned}
\dot{\mathrm{V}}= & g(x, t) \sum_{j=1}^{N}\left(\widehat{w}_{j}-w_{j}^{*}\right)\left(\dot{\widehat{w}}_{j}+\left.S_{x} \frac{\partial \Psi}{\partial w_{j}}\right|_{w_{j}=\widehat{w}_{j}}\right) \\
& +g(x, t) S_{x} b_{x}(t)-g(x, t) S_{x}\left[e_{f}\left(\chi_{x}\right)+\delta_{u_{x}}(t)\right] \\
& +\frac{1}{2} \dot{g}(x, t) \sum_{j=1}^{N}\left(\widehat{w}_{j}-w_{j}^{*}\right)^{2}-g(x, t) \frac{S_{x}^{2}}{\varepsilon_{x}}
\end{aligned}
$$

If the terms $b_{x}(t)$, the learning rule of the weight $w$, and the adaptive law for the unknown bound $\lambda_{x}$ are given by (15)(17), the following inequalities hold:

$$
\begin{aligned}
\dot{\mathrm{V}} \leq & -\left(\widehat{\lambda}_{x}-\lambda_{x}\right)\left|S_{x}\right|-g(x, t) \frac{S_{x}^{2}}{\varepsilon_{x}} \\
& +\frac{1}{2} \dot{g}(x, t) \sum_{j=1}^{N}\left(\widehat{w}_{j}-w_{j}^{*}\right)^{2} .
\end{aligned}
$$

The above inequality (21) can also be rewritten as

$$
\begin{aligned}
S_{x} \dot{S}_{x} \leq & -\left(\widehat{\lambda}_{x}-\lambda_{x}\right)\left|S_{x}\right|-g(x, t) \frac{S_{x}^{2}}{\varepsilon_{x}} \\
& +\frac{1}{2} \dot{g}(x, t) \sum_{j=1}^{N}\left(\widehat{w}_{j}-w_{j}^{*}\right)^{2} \\
& +g(x, t) \sum_{j=1}^{N}\left|\left(\widehat{w}_{j}-w_{j}^{*}\right)\right|\left|\frac{\partial \Psi}{\partial w_{j}}\right|_{\omega_{j}=\widehat{w}_{j}}|| S_{x} \mid .
\end{aligned}
$$

From the fact that $\widehat{\omega}_{j}, j=1, \ldots, N$ are bounded by construction, one can conclude that all the terms $\mid \widehat{\omega}_{j}-$ $\left.\omega_{j}^{*}||\left(\partial \Psi / \partial w_{j}\right)\right|_{w_{j}=\widehat{w}_{j}} \mid$ are bounded. 
From (17), it is clear that

$$
\hat{\lambda}_{x}=\alpha_{x} t+\hat{\lambda}_{x}(0) .
$$

Consequently, there exists a finite time $T_{f x}$ such that $\hat{\lambda}_{x}$ satisfies the inequality

$$
\widehat{\lambda}_{x}>\lambda_{x}+g(x, t) \sum_{j=1}^{N}\left|\left(\widehat{w}_{j}-w_{j}^{*}\right)\right|\left|\frac{\partial \Psi}{\partial w_{j}}\right|_{\omega_{j}=\widehat{w}_{j}} \mid
$$

and by taking into account Assumption 2, the neural network controller error $S_{x}$ will converge in finite time to the origin.

Remark 7. In the case where $g(x, t)<0 \forall x$, the Lyapunov candidate function (18), Assumption 2 are replaced by

$$
\mathrm{V}=\frac{1}{2} S_{x}^{2}-\frac{1}{2} g(x, t) \sum_{j=1}^{N}\left(\widehat{w}_{j}-w_{j}^{*}\right)^{2},
$$

$\dot{g}(x, t) \geq 0$, respectively, and the term $b_{x}(t)$ is substituted by

$$
b_{x}(t)=\widehat{\lambda}_{x} \operatorname{sgn}\left(S_{x}\right) .
$$

Remark 8. In the case where the sign of $\dot{g}(x, t) \geq 0$ is not constant, the tracking error converges to the ball with radius proportional to $1 / \widehat{\lambda}_{x}$.

Remark 9. Under realistic operation conditions, the neural network controller error $S_{x}$ converges to the neighborhoods of zero and $\hat{\lambda}$ will always increase. Therefore, the following choice for $\dot{\hat{\lambda}}_{x}$ is used instead of (17):

$$
\dot{\hat{\lambda}}_{x}= \begin{cases}\alpha_{x} & \text { if }\left|S_{x}\right| \geq \xi_{x} \\ 0 & \text { if }\left|S_{x}\right|=\xi_{x}\end{cases}
$$

where $\xi_{x}>0$ is the optimum neural network controller error under realistic operation conditions.

The block-diagram of the RBF neural network controller is depicted in Figure 1.

\section{Generator Side Control and Control Objective}

3.1. Wind Turbine Mathematical Model and Nonlinear Dynamics of Induction Generator. The power captured by turbine is given by

$$
P_{t u r}=\frac{1}{2} \pi \rho R^{2} C_{p}(\zeta) v^{3}
$$

where

$$
\zeta=\frac{R \omega_{m t u r}}{v}=\frac{R \omega_{m}}{G v} .
$$

In (28) and (29), $R$ is the turbine radius, $\rho$ is the air density, $v$ is the wind speed, $C_{p}(\zeta)$ is the power coefficient, $\zeta$, is the tip-speed ratio (TSR), $\omega_{m t u r}$ is the turbine rotor speed, $\omega_{m}$ is the generator rotor speed, and $G$ is the gearbox ratio. The following characterization of $C_{p}$ taken from [21] is used:

$$
C_{p}(\zeta)=\left(\frac{t_{2}}{\zeta}-t_{3}\right) e^{-t_{1} / \zeta}+t_{4} \zeta
$$

with $t_{1}=18.4, t_{2}=110.23, t_{3}=9.636$, and $t_{4}=10.22$

For maximum power extraction, maximum $C_{p}$ (i.e., $C_{p}^{*}$ ) is achieved if the rotor speed is maintained at an optimal value of $\zeta^{*}$. This value is obtained by solving (29) for $\omega_{m t u r}$ :

$$
\omega_{m t u r}^{*}=\frac{\zeta^{*} v}{R}
$$

The grid active power which equivalent to the optimal active power extracted is expressed as

$$
P^{*}=K_{o} \omega_{m t u r}^{* 3}
$$

Therefore regulating the rotor speed to its optimal value for any given wind speed is the main control objective.

The rotor dynamic is given by

$$
J_{t u r} \frac{d \omega_{m}}{d t}=\frac{T_{t u r}}{n_{g}}-T_{e} m-f \omega_{m}
$$

The wind turbine characteristics used in this work is given in Appendix B

SEIG dynamics is given by

$$
\begin{aligned}
\dot{i}_{s d} & =-a_{1} i_{s d}+\omega_{s} i_{s q}+a_{2} \varphi_{r o t}+\mu v_{s d} \\
\dot{i}_{s q} & =-\omega_{s} i_{s d}-a_{1} i_{s q}-a_{3} \omega \varphi_{r o t}+\mu v_{s q} \\
\dot{\varphi}_{r o t} & =\frac{M}{\tau_{r o t}} i_{s d}-\frac{1}{\tau_{r o t}} \varphi_{r o t} \\
\omega_{s} & =\omega+\frac{L_{m}}{\tau_{r o t}} \frac{i_{s q}}{\varphi_{r o t}}, \\
\theta_{s} & =\int \omega_{s} d t \\
v_{s d} & =\frac{1}{2} S_{d} v_{d c}, \\
v_{s q} & =\frac{1}{2} S_{q} v_{d c}, \\
T_{e m} & =n_{p} \frac{L_{m}}{L_{r o t}} \varphi_{r o t} i_{s q} \\
\dot{v}_{d c} & =-\frac{1}{2 C}\left(S_{d} i_{s d}+S_{q} i_{s q}\right)-\frac{S_{\alpha} v_{d c}}{R_{L} C}-\frac{i_{i n v}}{C}
\end{aligned}
$$




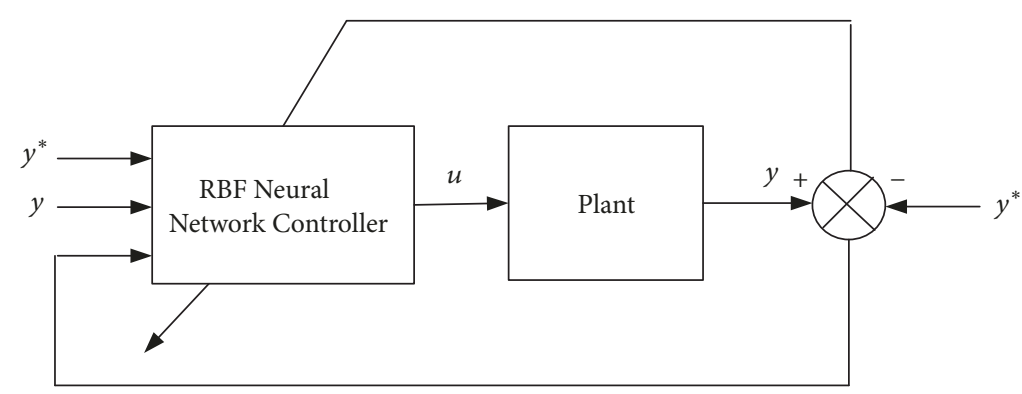

FIGURE 1: Radial basis function neurosliding mode controller block-diagram.

with

$$
\begin{aligned}
\sigma & =1-\frac{L_{m}^{2}}{L_{s} L_{r o t}}, \\
\tau_{s} & =\frac{L_{s}}{r_{s}}, \\
\tau_{r o t} & =\frac{L_{r o t}}{R_{r o t}}, \\
\mu & =\frac{1}{\sigma L_{s}} \\
a_{1} & =\frac{1}{\sigma \tau_{s}}+\frac{1-\sigma}{\sigma \tau_{r o t}}, \\
a_{2} & =\frac{1-\sigma}{L_{m} \sigma \tau_{r o t}}, \\
\text { and } a_{3} & =\frac{1-\sigma}{L_{m} \sigma} .
\end{aligned}
$$

In the above equations, $f$ is the sum of turbine external damping, $T_{t}$ and $T_{e m}$ are the aerodynamic and electromagnetic torques, and $J_{t}$ is the turbine total inertia. $\varphi_{\text {rot }}=\varphi_{\text {rotd }}$ is the rotor flux magnitude, $i_{s d}$ and $i_{s q}$ are the stator currents components, $v_{s d}$ and $v_{s q}$ are the stator voltages, $\omega$ is the rotor speed, and $\omega_{s}$ is the synchronous frame velocity. The parameters are rotor and stator winding resistances $\left(R_{\text {rot }}, R_{s}\right)$, inductances $\left(L_{r o t}, L_{s}\right)$, and mutual inductance $L_{m}$. $C, R$, and $R_{L}$ are the DC bus capacitor, main load, and dump load resistances, respectively. $T_{e m}$ is the electromagnetic torque and $n_{p}$ is the number of pole pairs. The measured variables are $\left(\omega, i_{s a}\right.$, and $\left.i_{s b}\right)$ while $\varphi_{\text {rot }}$ and $R_{\text {rot }}$ are not measurable. The control inputs are the stator voltages $\left(v_{s d}, v_{s q}\right.$, and $\left.v_{\alpha}\right)$ and the output to be controlled are the rotor flux $\varphi_{\text {rot }}$ and the DC voltage $v_{d c}$.

$S_{d}$ and $S_{q}$ are the $d, q$ coordinate frame transformation of the switching functions $S_{a}, S_{b}$, and $S_{c}$ for the PWM technique. The state of $S_{k}, k=a, b, c$ is defined by the following function:

$$
S_{k}= \begin{cases}+1, & \bar{S}_{k}=-1 \\ -1, & \bar{S}_{k}=+1\end{cases}
$$

To achieve the control objectives on the generator side, the following two assumptions will be considered.
Assumption $i$. The current and voltage signals from the stator are bounded.

Assumption ii. The rotor resistance $R_{\text {rot }} \in \Omega_{R_{\text {rot }}}$, where $\Omega_{R_{\text {rot }}}$ is a compact set of $\mathfrak{R}$.

Let us denote by $\varphi_{r o t}^{r e f}, \omega_{m}^{r e f}$, and $V_{d c}^{r e f}$ the smooth bounded reference signals for the rotor flux magnitude, generator rotor speed, and DC voltage to be controlled, respectively.

Our goal is to obtain maximum power from the turbine and to design the DC voltage, rotor flux, and generator rotor speed controllers assuming that the measured output is $\left(\omega_{m}, i_{s a}, i_{s b}\right)$ by choosing $\left(v_{s d}, v_{s q}, v_{\alpha}\right)$ such that, under large variation of the wind turbine velocity (within admissible range) and for any unknown but bounded $R_{r}$, we have

$$
\lim _{t \rightarrow \infty}\left[\begin{array}{c}
\varphi_{r o t} \\
\omega_{m} \\
V_{d c}
\end{array}\right]=\left[\begin{array}{c}
\varphi_{r o t}^{r e f} \\
\omega_{m}^{r e f} \\
V_{d c}^{r e f}
\end{array}\right]
$$

despite uncertainties on the electrical parameters.

3.2. RBF Neurosliding Mode Technique Control Design for SelfExcited Induction Generator. In this section, we recall the most important results related to RBF neurosliding-mode which have been used for the control of self-excited induction generator (SEIG) [10]. The choice of the RBF Neurosliding control strategy for the generator side is motivated by the fact that the method is simple and has very attractive characteristics despite the parametric uncertainties and model inaccuracies. In addition, it also requires very few resources (computer resources) for its implementation in contrast to advanced control methods such as fuzzy control and neural network control.

3.2.1. Nonadaptive Control Strategy. Equations (36) and (33) do not contain the stator voltage as an input. Thus these equations can not be used to derive the rotor flux and rotor speed controller of the SEIG. In order to apply the technique developed in Section 2 to design the rotor flux and rotor speed RBF neural network controllers for the SEIG, the transformations describe in (43) are used to make the stator voltage appear explicitly as input in both (36) and (33). To achieve this control task the following additive assumption is required. 
Assumption iii. The stator and rotor resistances vary slowly. This assumption means that the terms containing $d R_{\text {rot }} / d t$ and $d R_{s} / d t$ are negligible or small with respect to other existing terms.

Using Assumptions $i$-iii and the second time-derivative of $\phi_{r}$, the rotor flux equation containing the stator voltage component $v_{s d}$ as a control input is derived from (34) and (36) as

$$
\frac{d^{2} \varphi_{r o t}}{d t^{2}}=f_{\varphi_{r o t}}+g_{\varphi_{r o t}} v_{s d}+d_{\varphi_{r o t}}(t)
$$

with

$$
\begin{aligned}
f_{\varphi_{\text {rot }}} & =m_{1} i_{s d}+m_{2} i_{s q}+m_{3} \varphi_{\text {rot }}, \\
g_{\varphi_{\text {rot }}} & =m_{4} \\
m_{1} & =-\left(\frac{M a_{1}}{\tau_{\text {rot }}}+\frac{L_{m}}{\tau_{\text {rot }}^{2}}\right), \\
m_{2} & =\frac{L_{m} \omega_{s}}{\tau_{r o t}}, \\
m_{3} & =\frac{L_{m} a_{2}}{\tau_{r o t}^{2}}+\frac{1}{\tau_{r o t}^{2}}, \\
m_{4} & =\frac{\nu L_{m}}{\tau_{r o t}}
\end{aligned}
$$

where $d_{\phi_{\text {rot }}}(t)$ has been added in (43) to represent system uncertainties.

In order to derive the dynamic equation for the rotor speed regulation, let us rewrite (33) as follows:

$$
\frac{d \omega_{m}}{d t}=\frac{T_{t u r}}{J_{t u r} G}-\frac{T_{e m}}{J_{t u r}}-\frac{f}{J_{t u r}} \omega_{m},
$$

Motivated by [22], we replace $T_{t}$ in (45) by the following expression:

$$
T_{t u r_{o}}=k_{o}\left(\omega_{m}\right)^{2} \quad \text { with } k_{o}=\frac{\rho \pi R^{5} C_{p}^{*}}{2 \zeta^{* 3} G^{2}} .
$$

Using (45), (35), (38), and the second time-derivative of $\omega_{m}$ yields

$$
\frac{d^{2} \omega_{m}}{d t^{2}}=f_{\omega_{m}}+d_{9} v_{s q}+d_{\omega_{m}}(t)
$$

with

$$
\begin{aligned}
f_{\omega_{m}}= & d_{1} \omega_{m}^{3}+d_{2} \omega_{m}^{2}+d_{3} \omega_{m}+d_{4} \omega_{m} \varphi_{r o t} i_{s q} \\
& +d_{5} \varphi_{r o t} i_{s q}+d_{6} i_{s d} i_{s q}+d_{7} \omega_{s} \varphi_{r o t} i_{s d} \\
& +d_{8} \omega_{m} \varphi_{r o t}^{2}, \\
g_{\omega_{m}}= & d_{9} \\
d_{1}= & \frac{2 k_{o}^{2}}{J_{t u r}^{2} G^{2}}
\end{aligned}
$$

$$
\begin{aligned}
& d_{2}=\frac{3 f k_{o}}{J_{\text {tur }}^{2} G}, \\
& d_{3}=\frac{f^{2}}{J_{\text {tur }}^{2}} \\
& d_{4}=\frac{-2 n_{p} L_{m} k_{o}}{J_{t u r}^{2} n_{g} L_{r o t}}, \\
& d_{5}=\frac{n_{p} L_{m}}{J_{t u r} L_{r o t}}\left(\frac{f}{J_{t u r}}+\frac{1}{\tau_{r o t}}+a_{1}\right), \\
& d_{6}=\frac{-n_{p} L_{m}^{2}}{J_{t u r} L_{r o t} \tau_{r o t}}, \\
& d_{7}=\frac{n_{p} L_{m}}{J_{t u r} L_{r o t}}, \\
& d_{8}=\frac{n_{p}^{2} a_{3} L_{m}}{J_{t u r} L_{r o t}}, \\
& d_{9}=\frac{-n_{p} L_{m} \nu \varphi_{r o t}}{J_{t u r} L_{r o t}} .
\end{aligned}
$$

where $d_{\omega_{m}}(t)$ has been added in (47) to represent system uncertainties.

Therefore, (43) and (47) can be rewritten as follows:

$$
\begin{aligned}
& \dot{x}_{1 \varphi_{\text {rot }}}=x_{2 \varphi_{\text {rot }}} \\
& \dot{x}_{2 \varphi_{\text {rot }}}=f_{\varphi_{\text {rot }}}(t)+g_{\varphi_{\text {rot }}}(t) u_{\varphi_{\text {rot }}}+d_{\varphi_{\text {rot }}}(t) \\
& y_{\varphi_{\text {rot }}}=x_{1 \varphi_{\text {rot }}} \\
& \dot{x}_{1 \omega_{m}}=x_{2 \omega_{m}} \\
& \dot{x}_{2 \omega_{m}}=f_{\omega_{m}}(t)+g_{\omega_{m}}(t) u_{\omega_{m}}+d_{\omega_{m}}(t) \\
& y_{\omega_{m}}=x_{1 \omega_{m}}
\end{aligned}
$$

In order to derive the dc-link voltage control strategy, an Electronic Load Controller (ELC) is proposed. It consists of an insulated gate bipolar transistor IGBT operating as a chopper connected in series with a dump load resistance $R_{L}$ (heater or charging battery). It is designed to consume the maximum output power of the generator during a fault or overgeneration (i.e., when the duty cycle of the chopper is unity).

The dynamic behavior of the DC bus voltage obtained from the power balance principle is given by [23]

$$
\frac{C}{2} \frac{d v_{d c}^{2}}{d t}=\omega_{m} T_{e m}-\frac{S v_{d c}^{2}}{R_{L}}-P_{i n}
$$

where $P_{\text {in }}$ is the power input of the inverter. 
Equation (51) can also be written as

$$
\begin{aligned}
\frac{d v_{d c}}{d t} & =f_{v_{d c}}+g_{v_{d c}} z_{d c}+d_{v_{d c}}(t), \text { with } z_{v_{d c}}=S v_{d c} \\
f_{v_{d c}} & =\frac{\omega_{m} T_{e m}}{C v_{d c}}-\frac{P_{i n}}{C v_{d c}},
\end{aligned}
$$$$
\text { and } g_{v_{d c}}=-\frac{1}{R_{L} C}
$$

where $d_{v_{d c}}(t)$ has been added in (51) to represent system uncertainties.

The dynamics in (52) can then be expressed as follows:

$$
\begin{aligned}
& \dot{x}_{v_{d c}}=f_{v_{d c}}(t)+g_{v_{d c}}(t) z_{d c}+d_{v_{d c}}(t) \\
& y_{v_{d c}}=x_{v_{d c}} \\
& x_{v_{d c}}=v_{d c}
\end{aligned}
$$

Since $g_{\varphi_{r}}$ is strictly positive, while $g_{\omega_{m}}$ and $g_{v_{d c}}$ are strictly negative, the sliding-neural controller for the rotor flux regulation is given as

$$
\begin{aligned}
& \widehat{z}_{\varphi_{\text {rot }}}^{*}\left(\chi_{\varphi_{\text {rot }}}, t\right)=\Psi\left(\chi_{\varphi_{\text {rot }}}, \widehat{w}_{\varphi_{\text {rot }}}\right)+b_{\varphi_{\text {rot }}}(t), \\
& \chi_{\varphi_{\text {rot }}}^{T}=\left(\varphi_{\text {rot }}, S_{\varphi_{\text {rot }}}, \frac{S_{\varphi_{\text {rot }}}}{\varepsilon_{\varphi_{\text {rot }}}}\right) \text {, } \\
& S_{\varphi_{\text {rot }}}=l_{\varphi_{\text {rot }}} e_{\varphi_{\text {rot }}}+\dot{e}_{\varphi_{\text {rot }}} \\
& b_{\varphi_{\text {rot }}}(t)=-\hat{\lambda}_{\varphi_{\text {rot }}} \operatorname{sgn}\left(S_{\varphi_{\text {rot }}}\right) \\
& \dot{\widehat{w}}_{\varphi_{\text {rot }} j}=\operatorname{Proj}\left[-\left.S_{\varphi_{\text {rot }}} \frac{\partial \Psi}{\partial w_{\varphi_{\text {rot }} j}}\right|_{w_{\varphi_{\text {rot }} j}=\widehat{w}_{\varphi_{r o t} j}}\right] \text {, } \\
& j=1, \ldots, N
\end{aligned}
$$

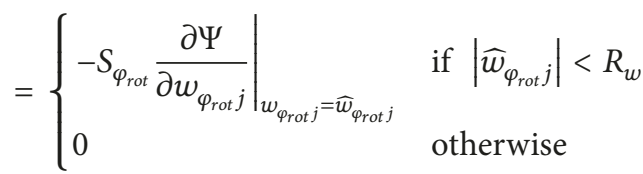

$$
\begin{aligned}
& \dot{\hat{\lambda}}_{\varphi_{\text {rot }}}= \begin{cases}\alpha_{\varphi_{\text {rot }}} & \text { if } S_{\varphi_{\text {rot }}} \neq 0 \\
0 & \text { if } S_{\varphi_{\text {rot }}}=0\end{cases}
\end{aligned}
$$

while the sliding-neural controllers for the rotor speed and DC-link voltage regulation are given by

$$
\begin{aligned}
& \widehat{z}_{\omega_{m}}^{*}\left(\chi_{\omega_{m}}, t\right)=\Psi\left(\chi_{\omega_{m}}, \widehat{w}_{\omega_{m}}\right)+b_{\omega_{m}}(t) \\
& \chi_{\omega_{m}}^{T}=\left(\omega_{m}, S_{\omega_{m}}, \frac{S_{\omega_{m}}}{\varepsilon_{\omega_{m}}}\right) \\
& S_{\omega_{m}}=l_{\omega_{m}} e_{\omega_{m}}+\dot{e}_{\omega_{m}}
\end{aligned}
$$

$$
\begin{aligned}
& b_{\omega_{m}}(t)=\hat{\lambda}_{\omega_{m}} \operatorname{sgn}\left(S_{\omega_{m}}\right) \\
& \dot{\widehat{w}}_{\omega_{m} j}=\operatorname{Proj}\left[-\left.S_{\omega_{m}} \frac{\partial \Psi}{\partial w_{\omega_{m} j}}\right|_{\omega_{\omega_{m} j}=\widehat{w}_{\omega_{m} j}}\right] \text {, } \\
& j=1, \ldots, N \\
& = \begin{cases}-\left.S_{\omega_{m}} \frac{\partial \Psi}{\partial w_{\omega_{m} j}}\right|_{w_{\omega_{m} j}=\widehat{w}_{\omega_{m} j}} & \text { if }\left|\widehat{w}_{\omega_{m} j}\right|<R_{w} \\
0 & \text { otherwise }\end{cases} \\
& \dot{\hat{\lambda}}_{\omega_{m}}= \begin{cases}\alpha_{\omega_{m}} & \text { if } S_{\omega_{m}} \neq 0 \\
0 & \text { if } S_{\omega_{m}}=0,\end{cases} \\
& \widehat{z}_{v_{d c}}^{*}\left(\chi_{v_{d c}}, t\right)=\Psi\left(\chi_{v_{d c}}, \widehat{w}_{v_{d c}}\right)+b_{v_{d c}}(t) \\
& \chi_{v_{d c}}^{T}=\left(v_{d c}, S_{v_{d c}}, \frac{S_{v_{d c}}}{\varepsilon_{v_{d c}}}\right) \text {, } \\
& S_{v_{d c}}=e_{v_{d c}} \\
& b_{v_{d c}}(t)=\hat{\lambda}_{v_{d c}} \operatorname{sgn}\left(S_{v_{d c}}\right) \\
& \dot{\widehat{w}}_{v_{d c j}}=\operatorname{Proj}\left[-\left.S_{v_{d c}} \frac{\partial \Psi}{\partial w_{v_{d c j}}}\right|_{w_{v_{d c j}}=\widehat{w}_{v_{d c j}}}\right], \quad j=1, \ldots, N \\
& = \begin{cases}-\left.S_{v_{d c}} \frac{\partial \Psi}{\partial w_{v_{d c j}}}\right|_{w_{v_{d c j}}=\widehat{w}_{v_{d c j}}} & \text { if }\left|\widehat{w}_{v_{d c j}}\right|<R_{w} \\
0 & \text { otherwise }\end{cases} \\
& \dot{\hat{\lambda}}_{v_{d c}}= \begin{cases}\alpha_{v_{d c}} & \text { if } S_{v_{d c}} \neq 0 \\
0 & \text { if } S_{v_{d c}}=0\end{cases}
\end{aligned}
$$

The relationship between the rotor flux linkage and rotor speed can be used to calculate the reference rotor flux linkage required at any speed as [24]

$$
\varphi_{\text {rot }}^{*}=\frac{\omega_{m_{\min }}}{\omega_{m}} \varphi_{r o t_{\max }}
$$

Remark 10. The computation of $S_{\varphi_{\text {rot }}},\left(i_{s d}, i_{s q}\right)$, and $\theta_{s}$ required the knowledge of the rotor resistance which is assumed to be unknown and time-varying. In the following section, estimation algorithms for $R_{r o t}, \varphi_{r o t}$, and $\theta_{s}$ will be described.

It should be noted that when the rotor speed falls below $\omega_{\min }$ in theory, the flux linkage is expected to increase to a value higher than $\varphi_{\text {rot }_{\text {max }}}$. However, once the saturation level is reached in an induction machine, the controller imposes the production of more flux from the direct axis current, $i_{s d}$. The magnitude of the exciting current can exceed the rated current of the machine without approaching the required reference flux. Hence, the generated voltage magnitude drops. 
Remark 11. In the above nonlinear controller, the stator electrical angular position and constraint function $s\left(\varphi_{\text {rot }}\right)$ are not available for online measurement because they depend upon the rotor flux and the rotor resistance which are assumed to be an unknown, time-varying parameter. Hence for the controller to be implementable in practice, online adaptation laws for $\tau_{\text {rot }}$ and $\varphi_{\text {rot }}$ are required.

3.2.2. Adaptive Design. The unknown time-varying rotor resistance required for the practical implementation of the above control scheme can be estimated using the method developed in [25]. To this end, let us consider the following dynamics of a balanced IM, expressed in a fixed reference frame $\alpha-\beta$ attached to the stator $[26,27]$ :

$$
\begin{aligned}
i_{s \alpha} & =\frac{1}{\gamma_{4}}\left(-L_{r o t} R_{s} i_{s \alpha}+L_{m}^{2} \omega i_{s \beta}+L_{m} R_{r o t} i_{\text {rot } \alpha}\right. \\
& \left.+L_{r o t} L_{m} \omega i_{r o t \beta}+L_{r o t} v_{s \alpha}\right) \\
\dot{i}_{s \beta} & =\frac{1}{\gamma_{4}}\left(-L_{m}^{2} \omega i_{s \alpha}-L_{r o t} R_{s} i_{s \beta}-L_{r o t} L_{m} \omega i_{\text {rot } \alpha}\right. \\
& \left.+L_{m} R_{r o t} i_{r o t \beta}+L_{r} v_{s \beta}\right) \\
i_{r o t \alpha} & =\frac{1}{\gamma_{4}}\left(L_{m} R_{s} i_{s \alpha}-L_{m} L_{s} \omega i_{s \beta}-L_{s} R_{r o t} i_{\text {rot } \alpha}\right. \\
& \left.-L_{s} L_{r o t} \omega i_{r \beta}+L_{m} v_{s \alpha}\right) \\
\dot{i}_{\text {rot } \beta} & =\frac{1}{\gamma_{4}}\left(L_{m} L_{s} \omega i_{s \alpha}+L_{m} R_{s} i_{s \beta}+L_{s} L_{r o t} \omega i_{r o t \alpha}\right. \\
& \left.-L_{s} R_{r o t} i_{r o t \beta}+L_{m} v_{s \beta}\right)
\end{aligned}
$$

where $a_{4}=L_{s} L_{r o t}-L_{m}^{2}$.

The rotor resistance estimator is given as

$$
\begin{gathered}
\dot{\hat{i}}_{s \alpha}=\frac{1}{\gamma_{4}}\left(-L_{r o t} R_{s} i_{s \alpha}+L_{m}^{2} \omega i_{s \beta}+L_{m} \widehat{R}_{r o t} \widehat{i}_{r o t \alpha}\right. \\
\left.+L_{m} L_{r o t} \omega \hat{i}_{r o t \beta}+L_{r o t} v_{s \alpha}\right)-K \operatorname{sign}\left(\widetilde{i}_{s \alpha}\right) \\
\dot{\hat{i}}_{s \beta}=\frac{1}{\gamma_{4}}\left(-L_{m}^{2} \omega i_{s \alpha}-L_{r o t} R_{s} i_{s \beta}-L_{m} L_{r o t} \omega \hat{i}_{r o t \alpha}\right. \\
\left.+L_{m} \widehat{R}_{r o t} \widehat{i}_{r o t \beta}+L_{r o t} v_{s \beta}\right)-K \operatorname{sign}\left(\widetilde{i}_{s \beta}\right) \\
\dot{\hat{i}}_{r o t \alpha}=\frac{1}{\gamma_{4}}\left(L_{m} R_{s} i_{s \alpha}-L_{m} L_{s} \omega i_{s \beta}-L_{s} \widehat{R}_{r o t} \hat{i}_{r o t \alpha}\right. \\
\left.\quad-L_{s} L_{r o t} \omega \hat{i}_{r o t \beta}+u_{\alpha}-L_{m} v_{s \alpha}\right) \\
\dot{\hat{i}}_{r o t \beta}=\frac{1}{\gamma_{4}}\left(L_{m} L_{s} \omega i_{s \alpha}+L_{m} R_{s} i_{s \beta}+L_{s} L_{r o t} \omega \hat{i}_{r o t \alpha}\right. \\
\left.\quad-L_{s} \widehat{R}_{r o t} \hat{i}_{r o t \beta}+u_{\beta}-L_{m} v_{s \beta}\right)
\end{gathered}
$$

$$
\begin{aligned}
& u_{\alpha}=-L_{s} \widetilde{R}_{r o t} \hat{i}_{r o t \alpha}, \\
& u_{\beta}=-L_{s} \widetilde{R}_{r} \hat{i}_{r o t \beta} \\
& \dot{\hat{R}}_{r o t}=K_{R_{r o t}} \operatorname{sign}\left(\widetilde{R}_{r o t}\right) \\
& \text { with } \widetilde{R}_{r o t}=\frac{\gamma_{4}\left(\widehat{i}_{r o t \alpha} W_{\alpha e q}+\widehat{i}_{r o t b} W_{\beta e q}\right)}{L_{m}\left(\hat{i}_{r o t \alpha}^{2}+\hat{i}_{r o t \beta}^{2}\right)} .
\end{aligned}
$$

The proof of the finite time convergence of the above rotor resistance estimator can be found in [25]. From the technique developed in [10], the rotor flux observer and stator electrical angular position are given by

$$
\dot{\hat{\varphi}}_{r o t}=\frac{L_{m} \widehat{R}_{r o t}}{L_{r o t}} i_{s d}-\frac{\widehat{R}_{r o t}}{L_{r o t}} \widehat{\varphi}_{r o t}
$$

and

$$
\begin{aligned}
& \widehat{\omega}_{s}=\omega+\frac{L_{m} \widehat{R}_{r o t}}{L_{r o t}} \frac{i_{s q}}{\widehat{\varphi}_{r o t}}, \\
& \widehat{\theta}_{s}=\int \widehat{\omega}_{s} d t .
\end{aligned}
$$

\section{Inverter Control Design}

An $L C L$ filter is used to connect the voltage source inverter to the grid. The equations governing the voltage source inverter connected to an AC load and grid through an LCL filter in the three-phase vector system are given as [23]

$$
\begin{aligned}
L_{1 f} \dot{i}_{i n v j} & =v_{j}-R_{1 f} i_{i n v j}-v_{i n v j} \\
C_{1 f} \dot{v}_{j} & =i_{i n v j}-i_{L j}-i_{g j} \\
L_{2 f} \dot{i}_{g j} & =v_{g j}-R_{2 f} i_{g j}-v_{j}
\end{aligned}
$$

Applying transformation on (72), (73), and (74), the model of voltage source inverter connected to an AC load and grid through an LCL filter in the synchronously rotation $(d, q)$ frame is given by

$$
\begin{gathered}
\dot{i}_{\text {invd }}=-\frac{R_{1 f}}{L_{1 f}} i_{\text {invd }}+\omega_{e} i_{\text {invq }}+\frac{1}{L_{1 f}} v_{\text {invd }}-\frac{1}{L_{1 f}} v_{d} \\
\dot{i}_{\text {invq }}=-\frac{R_{1 f}}{L_{1 f}} i_{\text {invq }}-\omega_{e} i_{\text {invd }}+\frac{1}{L_{1 f}} v_{i n v q}-\frac{1}{L_{1 f}} v_{q} \\
\dot{v}_{d}=\frac{1}{C_{f}} i_{\text {invd }}-\frac{1}{C_{f}} i_{L d}-\frac{1}{C_{f}} i_{d g} \\
\dot{v}_{q}=\frac{1}{C_{f}} i_{\text {invq }}-\frac{1}{C_{f}} i_{L q}-\frac{1}{C_{f}} i_{q g},
\end{gathered}
$$




$$
\begin{aligned}
\dot{i}_{d g}= & -\frac{R_{2 f}}{L_{2 f}} i_{d g}-\frac{R_{2 f}}{L_{2 f}} i_{L d}+\omega_{e}\left(i_{q g}+i_{L q}\right)+\frac{1}{L_{2 f}} v_{d} \\
& -\frac{1}{L_{2 f}} E_{d} \\
\dot{i}_{q g}= & -\frac{R_{2 f}}{L_{2 f}} i_{q g}-\frac{R_{2 f}}{L_{2 f}} i_{L q}+\omega_{e}\left(i_{d g}+i_{L d}\right)+\frac{1}{L_{2 f}} v_{q} \\
& -\frac{1}{L_{2 f}} E_{q} .
\end{aligned}
$$

$i_{\text {invd }}$ and $i_{\text {invq }}$ are currents components at the input of the inverter; $v_{d}$ and $v_{q}$ are load voltage components in $(d, q)$ coordinate frame. $i_{L d}, i_{L q}, i_{d g}$, and $i_{q g}$ are load and grid current components; $R_{f}, L_{f}$, and $C_{f}$ are $L C L$ filter resistor, inductor, and capacitor, respectively.

The control objective on the grid side is to synthesize a controller which regulates the amplitude and the frequency of the inverter voltage in stand-alone operation mode. Once the amplitude of the inverter's voltage is equal to its reference value and the voltage angle of the inverter synchronizes with that of the grid, the system switches automatically to the grid connected mode. Therefore the control objective becomes the regulation of the current injected into the grid in order to stabilize the system and guarantee a maximum power transfer. Grid synchronization is ensured using the PLL technique.

4.1. Grid Side Operation. The three-phase AC load is sized as to absorb a certain fixed amount of power and be supplied in priority. It is only when the wind speed that determines the available power on the wind turbine goes beyond a threshold value that grid connection is envisaged. The additional power captured can then be injected to the grid. The operating range for stand-alone mode is limited to wind speeds between $4 \mathrm{~m} / \mathrm{s}$ to $5 \mathrm{~m} / \mathrm{s}$ while grid connected mode starts when the wind speed is above $5 \mathrm{~m} / \mathrm{s}$. Thus switching from grid connected mode to isolated mode of operation is done using a wind speed threshold value

Stand-Alone Operation Mode. Considering that initially the system started in grid connected mode, then when the wind speed goes below a certain preset value, the produced power drops and hence the grid are disconnected and the system is connected to a three-phase AC load. The PWM inverter thus switches to the voltage controlled mode.

Once the PWM inverter is in the voltage controlled mode, the amplitude and frequency of the output voltage are controlled using two cascaded control loops with four PI regulators. Using $v_{d}^{*}$ and $v_{q}^{*}$ as the reference load voltage components in the synchronously rotating $d$ and $q$ axis reference frame, the four PI regulators can be easily designed to regulate the dq voltage components $v_{d}$ and $v_{q}$ using (75)(78).

The structure of the controller in a stand-alone mode operation is shown in Figure 2.
Grid Connected Operation Mode. Assuming that initially the system started in stand-alone mode, then when the wind speed exceeds a certain preset value, the power extracted from the wind turbine increases and hence the grid is connected to absorb the excess power produced. The PWM inverter switches to the current controlled mode which uses three cascaded control loops with six PI controllers to control the power transferred to the grid. The structure of the controller in the grid connected mode is shown in Figure 3.

For grid synchronization, the system uses an angle produced by the Phase Lock Loop (PLL). In this operation mode, the power extracted from the wind is transferred to the network through a standard AC/DC/AC converter which allows the controllability of certain parameters.

\subsection{Grid Side Controller Design}

Inverter Output Voltage Regulation. Equations (77) and (78) can be rewritten as

$$
\begin{aligned}
& C_{1 f} \dot{v}_{d}=i_{i n v d}^{\prime} \\
& C_{1 f} \dot{v}_{q}=i_{\text {invq }}^{\prime}
\end{aligned}
$$

where

$$
\begin{aligned}
& i_{\text {invd }}^{\prime}=i_{\text {invd }}-i_{L d}-i_{d g}+C_{1 f} \omega_{e} v_{q} \\
& i_{\text {invq }}^{\prime}=i_{\text {invq }}-i_{L q}-i_{q g}+C_{1 f} \omega_{e} v_{d}
\end{aligned}
$$

The transfer function of the system describe by (75) and (76) can be written as

$$
\begin{aligned}
& \frac{v_{d}(s)}{i_{\text {invd }}(s)}=\frac{1}{C_{1 f} s} \\
& \frac{v_{q}(s)}{i_{\text {invq }}(s)}=\frac{1}{C_{1 f} s}
\end{aligned}
$$

Each component of the output voltage in the above equation requires a separate PI regulator. The two PI regulators for the $v_{d}$ and $v_{q}$ voltage components are used to provide the reference current components $i_{\text {invd }}^{\text {ref }}$ and $i_{\text {invq }}^{\text {ref }}$, respectively. The transfer functions of the two PI regulators are also denote by $R_{v_{d}}(s)$ and $R_{v_{q}}(s)$, respectively.

Let $e_{v d}=v_{d}^{r e f}-v_{d}$ and $e_{v q}=v_{q}^{r e f}-v_{q}$ be the regulation errors for $v_{d}$ and $v_{q}$, respectively. Then the transfer functions of the regulators can be expresses as

$$
\begin{aligned}
R_{v_{d}}(s) & =\frac{K_{P_{v d}}\left(K_{I_{v d}} / K_{p_{v d}}+s\right)}{s} \\
R_{v_{q}}(s) & =\frac{K_{P_{v q}}\left(K_{I_{v q}} / K_{p_{v q}}+s\right)}{s}
\end{aligned}
$$




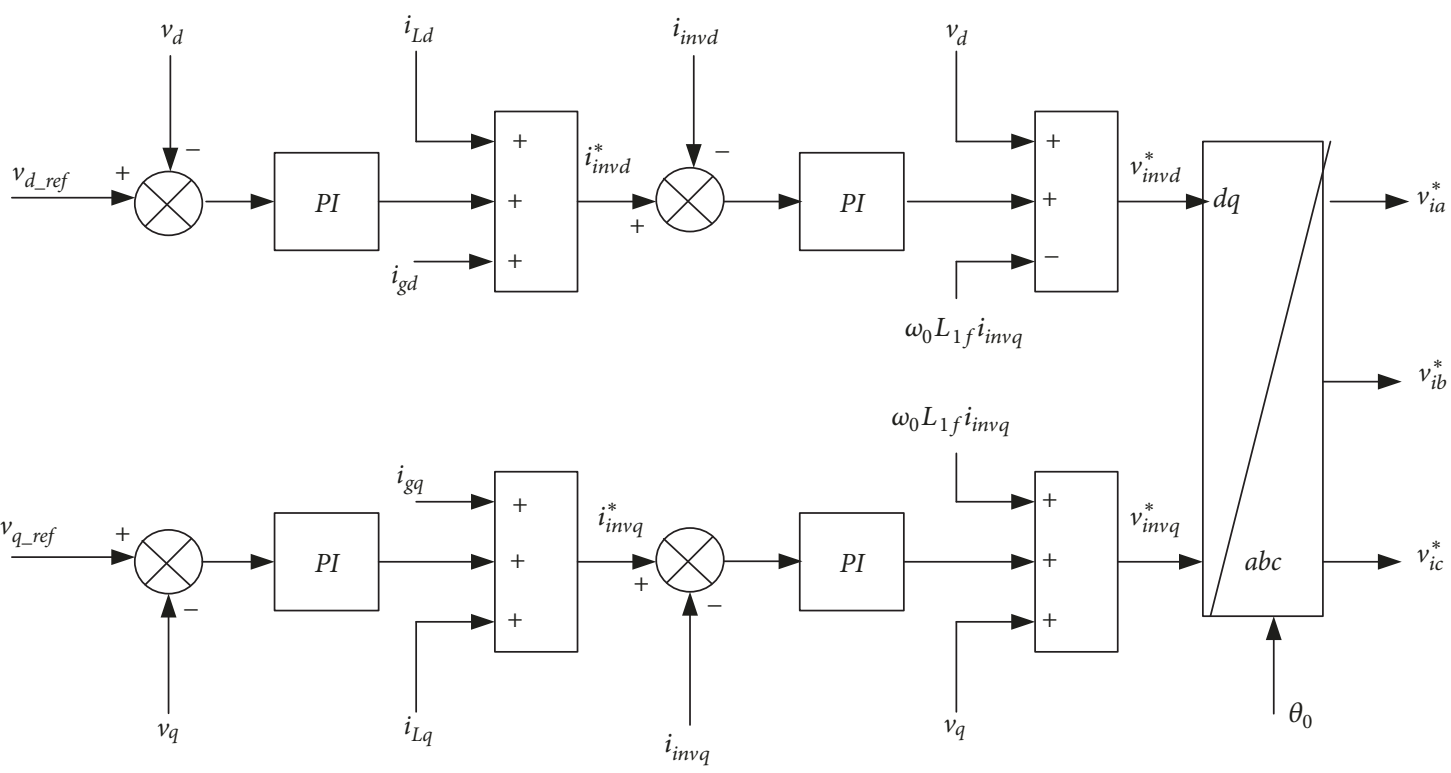

FIGURE 2: PI regulators used for load voltage control.

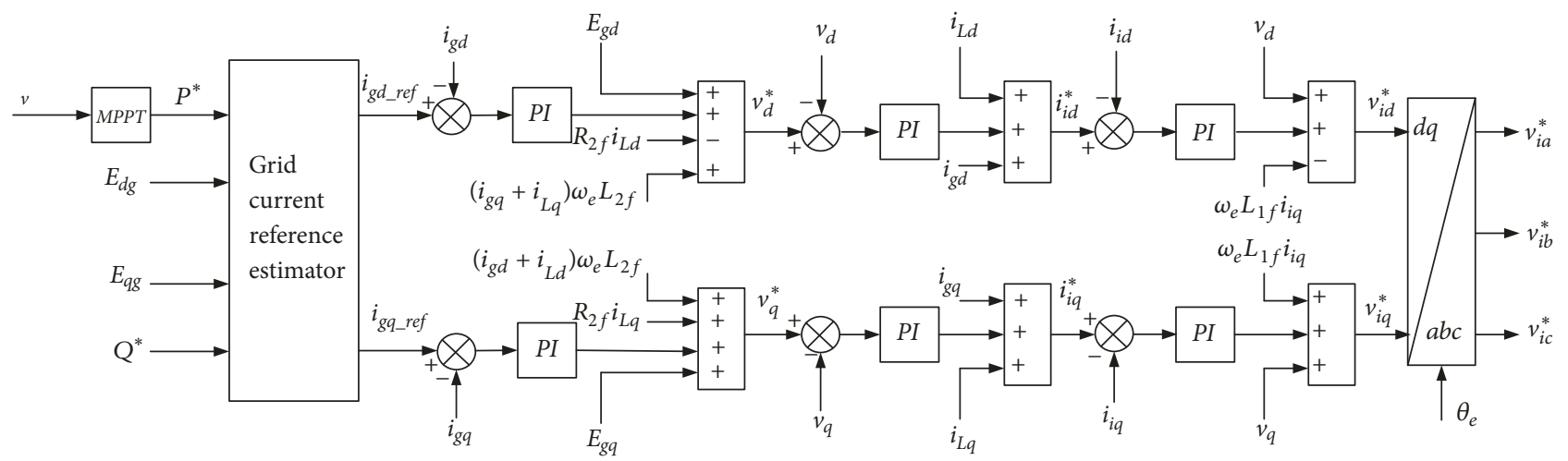

FIgURE 3: Structure of the PI regulators used for the control of the grid current.

From the above transfer functions, the corrected close-loop transfer functions (CCLTF(s)) can be computed as

$$
\begin{aligned}
& \operatorname{CCLTF}_{v d}(s)=\frac{1+\left(K_{P_{v d}} / K_{I_{v d}}\right) s}{1+\left(K_{P_{v d}} / K_{I_{v d}}\right) s+\left(C_{1 f} / K_{I_{v d}}\right) s^{2}} \\
& \operatorname{CCLTF}_{v q}(s)=\frac{1+\left(K_{P_{v q}} / K_{I_{v q}}\right) s}{1+\left(K_{P_{v q}} / K_{I_{v q}}\right) s+\left(C_{1 f} / K_{I_{v q}}\right) s^{2}}
\end{aligned}
$$

The above close-loop transfer function is a second-order system which can be compared with the standard secondorder transfer function given as

$$
F(s)=\frac{T(s)}{1+\left(2 \xi / \omega_{p}\right) S+\left(1 / \omega_{p}^{2}\right) s^{2}}
$$

In the standard second-order transfer function, $T(s)=$ $1+\left(K_{P_{v d}} / K_{I_{v d}}\right) s, \omega_{p}$ is the undamped natural frequency in $\mathrm{rad} / \mathrm{s}$, and $\xi$ is the unitless damping ratio. A comparison of CCLTF(s) and standard second-order transfer function leads to the following relationships:

$$
\begin{aligned}
& K_{P_{v d}}=2 \xi \omega_{p} C_{1 f} \\
& K_{I_{v d}}=\omega_{p}^{2} C_{1 f} \\
& K_{P_{v q}}=2 \xi \omega_{p} C_{1 f} \\
& K_{I_{v q}}=\omega_{p}^{2} C_{1 f}
\end{aligned}
$$

Inverter Current Regulation. In this case, (75) and (76) are rewritten as

$$
\begin{aligned}
& L_{1 f} \dot{i}_{i n v d}+R_{1 f} \dot{i}_{\text {invd }}=v_{i d}^{\prime} \\
& L_{1 f} \dot{i}_{i n v q}+R_{1 f} i_{\text {invq }}=v_{i n v q}^{\prime}
\end{aligned}
$$




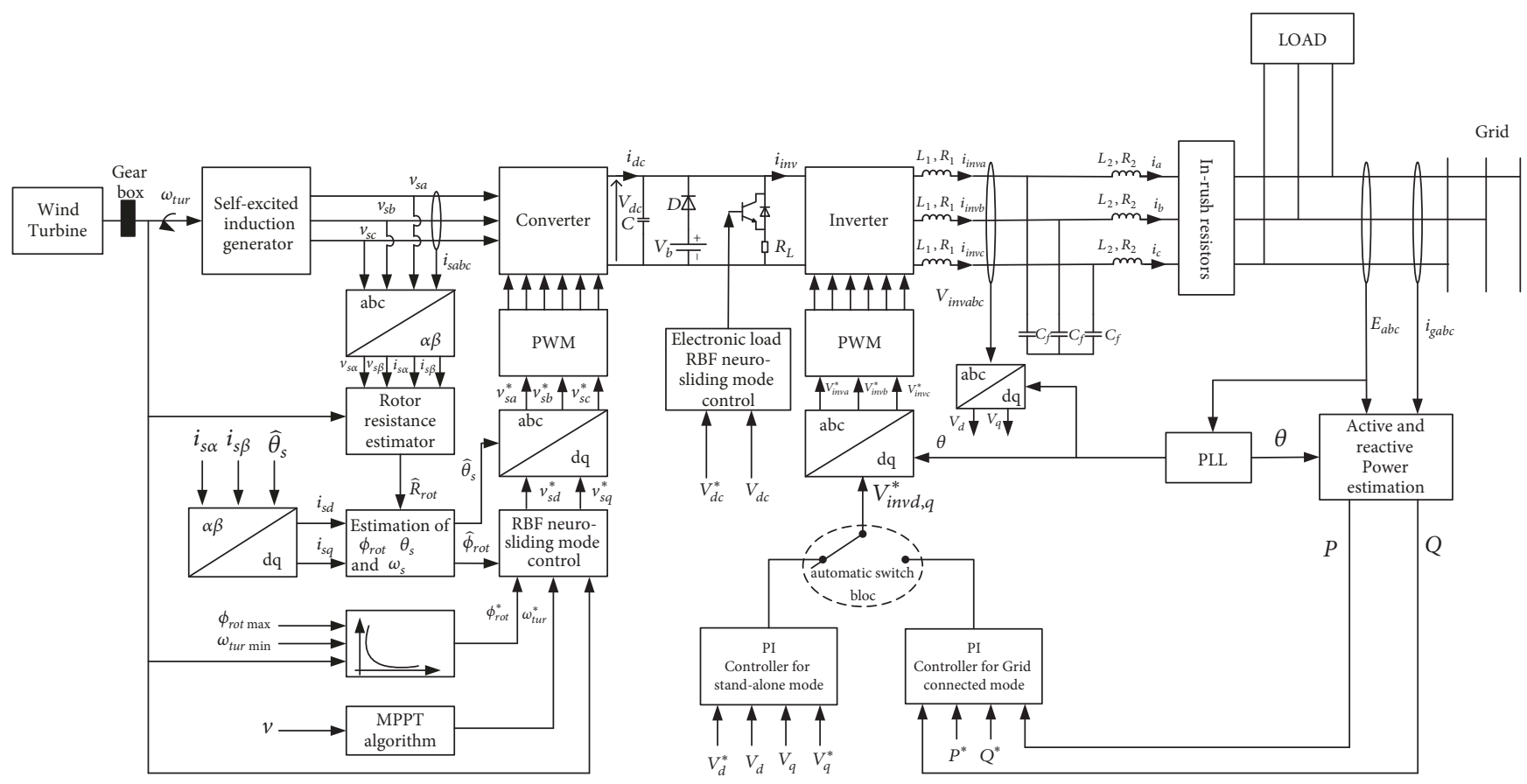

FIGURE 4: Structure of the overall studied system.

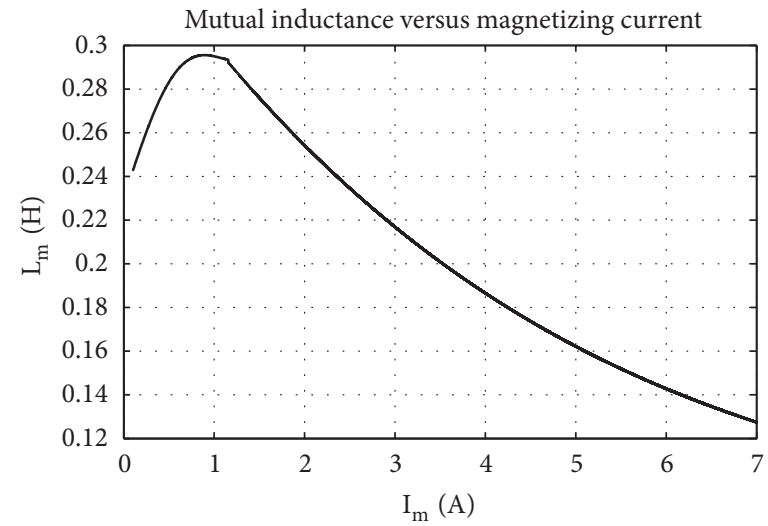

FIGURE 5: Variation of the mutual inductance with magnetizing current.

where

$$
\begin{aligned}
& v_{i n v d}^{\prime}=L_{1 f} \omega_{e} i_{i n v q}+v_{i n v d}+v_{d} \\
& v_{i n v q}^{\prime}=L_{1 f} \omega_{e} i_{i n v d}+v_{i n v q}+v_{q}
\end{aligned}
$$

The open loop transfer functions of (75) and (76) are given as

$$
\begin{aligned}
& \frac{i_{i n v d}}{v_{i n v d}^{\prime}}=\frac{1}{L_{1 f} \mathcal{S}+R_{1 f}} \\
& \frac{i_{\text {invq }}}{v_{\text {invq }}^{\prime}}=\frac{1}{L_{1 f} \mathcal{s}+R_{1 f}}
\end{aligned}
$$

where $s=d / d t$ is the Laplace operator.

Two PI regulators are designed to regulate the inverter current components $i_{\text {invd }}$ and $i_{\text {invq }}$. The two regulators provide the inverter voltage command component $v_{\text {invd }}^{*}$ and $v_{\text {invq }}^{*}$, respectively. The transfer functions for the PI regulators are express as

$$
\begin{aligned}
R_{i_{\text {invd }}}(s) & =\frac{K_{P_{i_{\text {invd }}}}\left(K_{I_{i_{\text {invd }}}} / K_{P_{i_{\text {invd }}}}+s\right)}{s} \\
R_{i_{\text {invq }}}(s) & =\frac{K_{P_{i_{\text {invq }}}}\left(K_{I_{i_{\text {invq }}}} / K_{P_{i_{\text {invq }}}}+s\right)}{s}
\end{aligned}
$$

where $K_{P_{i_{\text {invd }}}}$ and $K_{I_{i_{\text {invd }}}}$ are turning gains.

The tracking errors of the two current components $i_{\text {invd }}$ and $i_{\text {invq }}$ are defined as $e_{i_{\text {invd }}}=i_{\text {invd }}^{\text {ref }}-i_{\text {invd }}$ and $e_{i_{\text {invq }}}=i_{\text {invq }}^{\text {ref }}-i_{\text {invq }}$. 

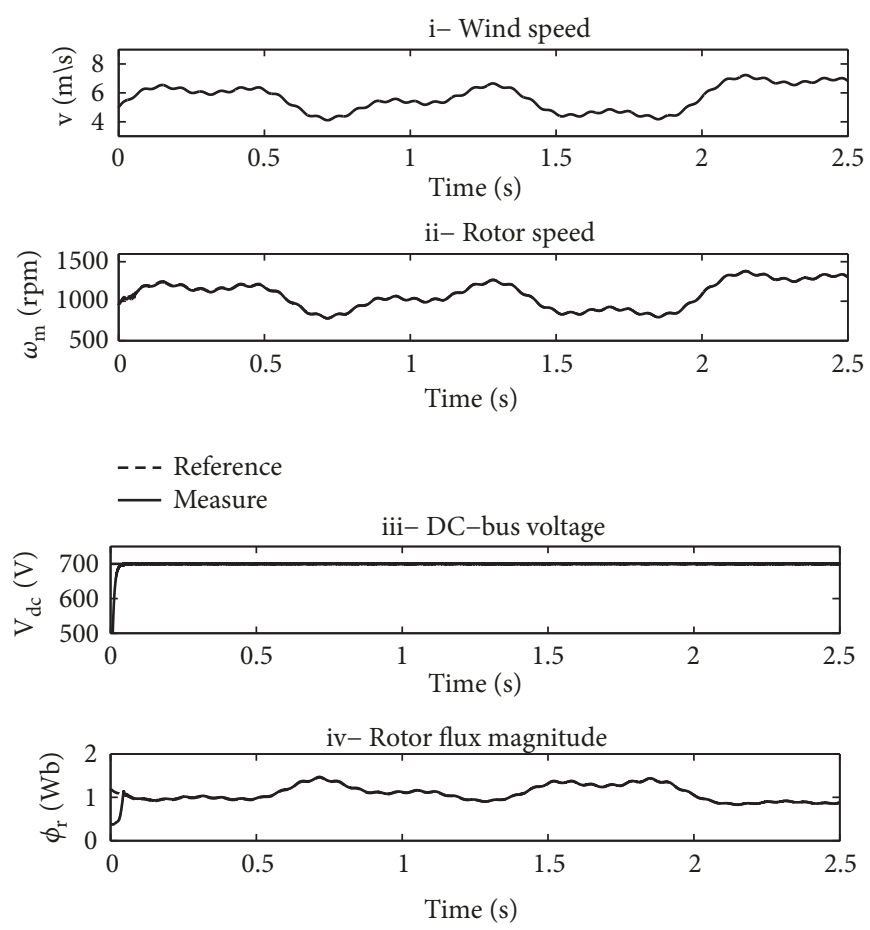

(a)
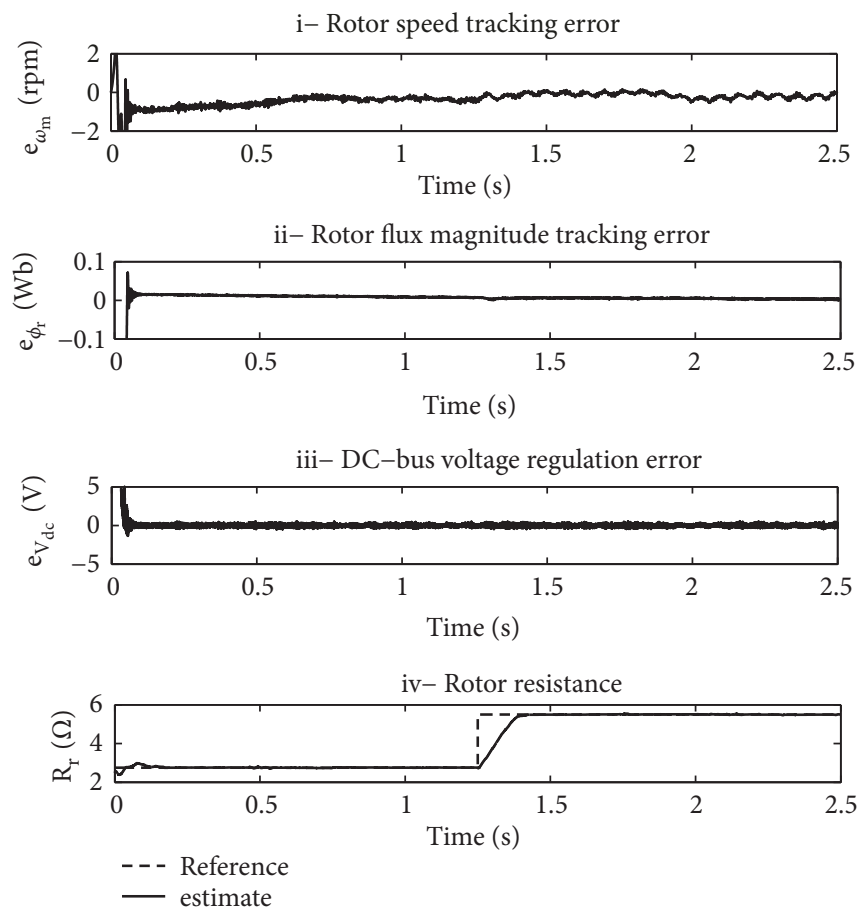

(b)

FIGURE 6: Performances of the generator side RBF neurosliding controllers under variation of the rotor speed and $100 \%$ online variation of rotor resistance. (a) Wind speed (i), rotor speed (ii), rotor flux magnitude (iii), and DC bus voltage (iv). (b) Rotor speed tracking error (i), rotor flux magnitude tracking error (ii), DC bus voltage regulation error (iii), and rotor resistance (iv). 

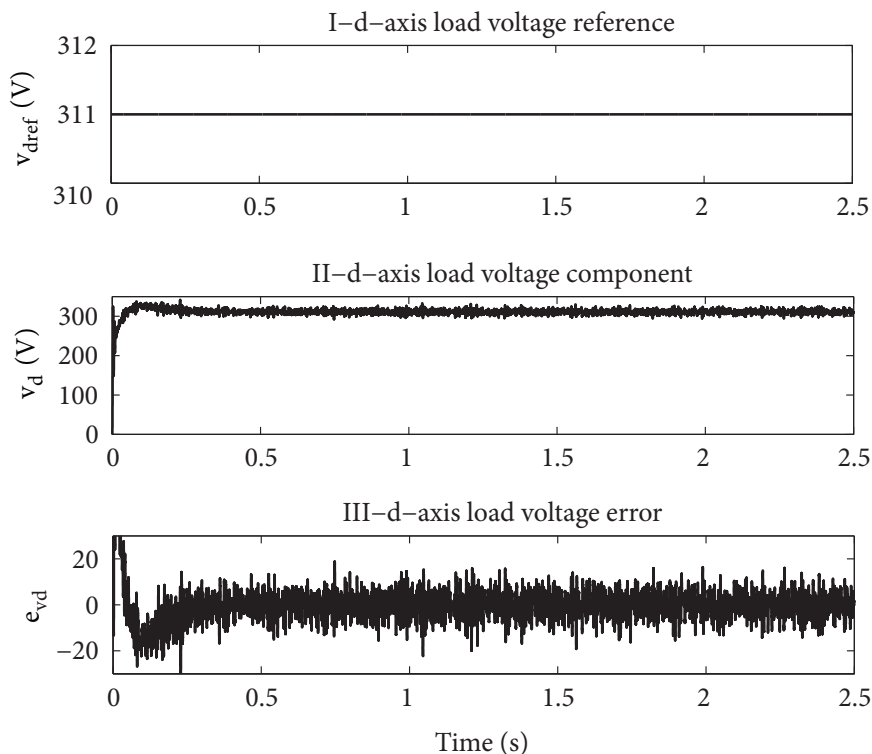

(a)
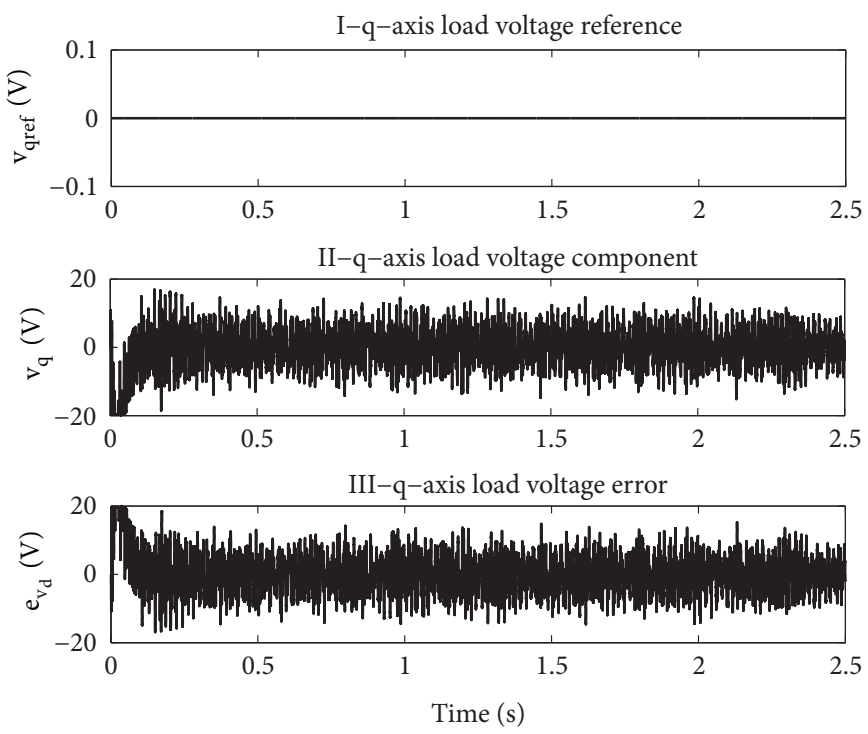

(b)

FIGURE 7: Performances of the inverter side PI controllers in stand-alone mode. (a) d-axis load voltage reference (i), d-axis load voltage component (ii), and d-axis load voltage error (iii). (b) q-axis load voltage reference (i), q-axis load component (ii), and q-axis load voltage error (iii).

From the transfer function of the regulator defined above, the open loop transfer function of this system can be written as

$$
\begin{aligned}
& \operatorname{OLTF}_{i_{\text {invd }}}(s) \\
& \quad=\frac{1 / L_{1 f}}{s+R_{1 f} / L_{1 f}} \frac{K_{P_{\text {invd }}}\left(K_{I_{i_{\text {invod }}}} / K_{P_{i_{\text {invd }}}}+s\right)}{s} \\
& \operatorname{OLTF}_{i_{\text {invq }}}(s)=\frac{1 / L_{1 f}}{s+R_{1 f} / L_{1 f}} \frac{K_{P_{i_{\text {invq }}}}\left(K_{I_{i_{\text {invq }}}} / K_{P_{i_{\text {invq }}}}+s\right)}{s}
\end{aligned}
$$

The compensation of the pole of the open loop transfer function by the zero of the transfer function of the PI regulator yields the following expressions:

$$
\begin{aligned}
& \frac{K_{I_{i_{\text {invd }}}}}{K_{P_{i_{\text {invd }}}}}=\frac{R_{1 f}}{L_{1 f}} \\
& \frac{K_{I_{i_{\text {invq }}}}}{K_{P_{i_{\text {invq }}}}}=\frac{R_{1 f}}{L_{1 f}}
\end{aligned}
$$

The corrected close-loop transfer function is given by 

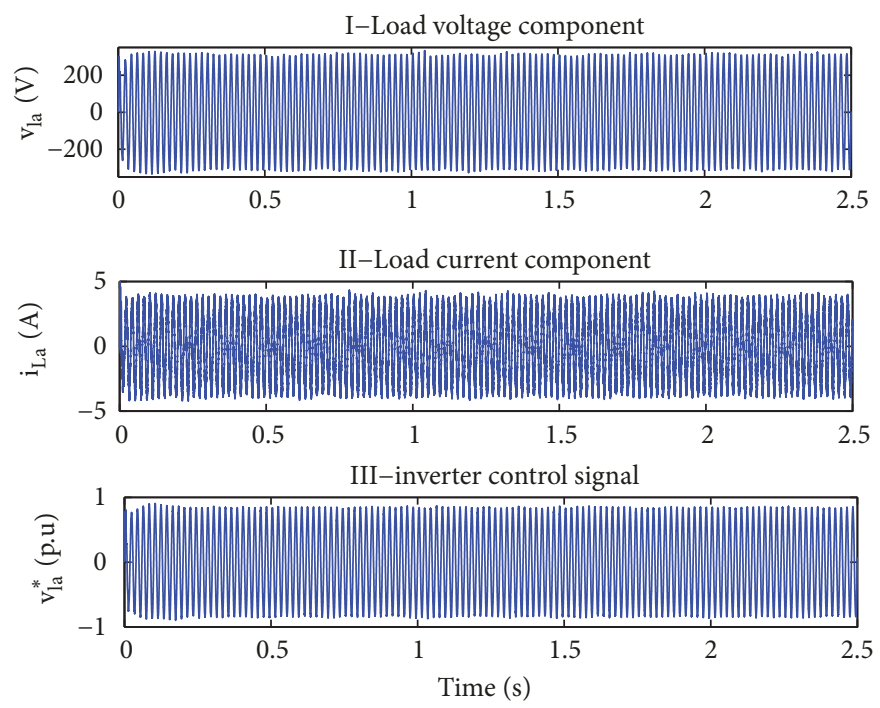

Figure 8: Performances of the inverter side PI controllers in stand-alone mode. Load phase voltage component (i), load phase current component (ii), and inverter control signal (iii).

$$
\begin{aligned}
& \operatorname{CCLTF}_{i_{\text {invd }}}(s)=\frac{1}{1+\left(L_{1 f} / K_{P_{i_{\text {invd }}}}\right) s} \\
& \operatorname{CCLTF}_{i_{\text {invq }}}(s)=\frac{1}{1+\left(L_{1 f} / K_{P_{i_{\text {invq }}}}\right) s}
\end{aligned}
$$

This transfer function is that of a first-order system with time constant $\tau_{i_{\text {invd }}}=L_{1 f} / K_{P_{i_{\text {invd }}}}$.

It is known that after a period of three times, the time constant (i.e., $3 x \tau$ ), the response of a first-order system is at $95 \%$ of its final value. For a first-order system, the response time at $5 \%$ can be approximated by $t_{r_{i_{\text {ind }}}}(5 \%)=3 \tau_{i_{\text {invd }}}$. We can then deduce the following parameters of the PI regulator from the $i_{\text {invd }}$ and $i_{\text {invq }}$ current components.

$$
\begin{aligned}
K_{P_{i_{\text {invd }}}} & =\frac{3 L_{1 f}}{t_{r_{i_{\text {invd }}}}(5 \%)}, \\
K_{I_{i_{\text {invd }}}} & =\frac{3 R_{1 f}}{t_{r_{i_{\text {invd }}}}(5 \%)} \\
K_{P_{i_{\text {invq }}}} & =\frac{3 L_{1 f}}{t_{r_{i_{\text {invq }}}}(5 \%)}, \\
K_{I_{i_{\text {invq }}}} & =\frac{3 R_{1 f}}{t_{r_{i_{\text {invq }}}}(5 \%)}
\end{aligned}
$$

Grid Current Regulation. The grid current references are estimated using the following expression [4]:

$$
\begin{aligned}
& i_{d g}^{r e f}=\frac{2}{3} \frac{Q^{r e f} E_{q}+P^{r e f} E_{d}}{E_{q}^{2}+E_{d}^{2}} \\
& i_{q g}^{r e f}=\frac{2}{3} \frac{P^{r e f} E_{q}-Q^{r e f} E_{d}}{E_{q}^{2}+E_{d}^{2}}
\end{aligned}
$$

where $P^{r e f}$ is the optimal active power that is directly extracted from the wind and $Q^{r e f}$ is the reference reactive power which must be set to 0 to ensure a unit power factor. From (79) to (80) two PI regulators can be design to regulate the grid current as presented in Figure 3.

Let (79) and (80) be rewritten as

$$
\begin{aligned}
& L_{2 f} \dot{i}_{d g}+R_{2 f} i_{d g}=v_{d}^{\prime} \\
& L_{2 f} \dot{i}_{q g}^{\cdot}+R_{2 f} i_{q g}=v_{q}^{\prime}
\end{aligned}
$$

where

$$
\begin{aligned}
& v_{d}^{\prime}=L_{2 f} \omega_{e}\left(i_{g q}+i_{L q}\right)-R_{2 f} i_{L d}-v_{d}+E_{g d} \\
& v_{q}^{\prime}=L_{2 f} \omega_{e}\left(i_{g d}+i_{L d}\right)-R_{2 f} i_{L q}-v_{q}+E_{g q}
\end{aligned}
$$

The open loop transfer function of system (79) and (80) is given by

$$
\begin{aligned}
& \frac{i_{g d}}{v_{d}^{\prime}}=\frac{1}{L_{2 f} s+R_{2 f}} \\
& \frac{i_{g q}}{v_{q}^{\prime}}=\frac{1}{L_{2 f} s+R_{2 f}}
\end{aligned}
$$

The same procedure described above has been used to design the PI regulators for the grid currents components $i_{g_{d}}$ and $i_{g_{q}}$.

The structure of the overall studied system is depicted in Figure 4. 

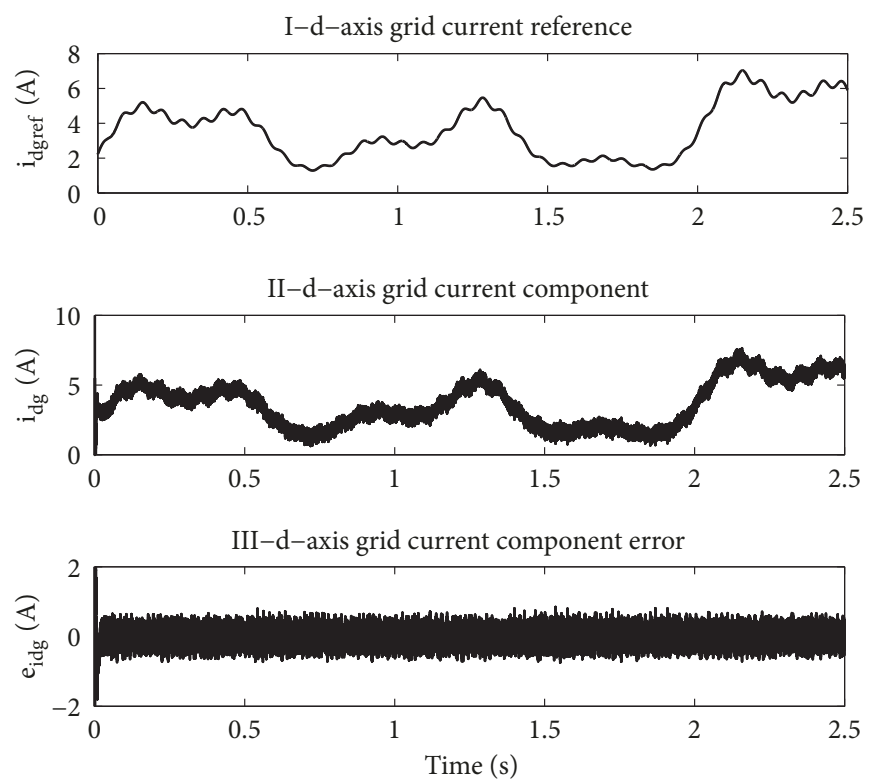

(a)
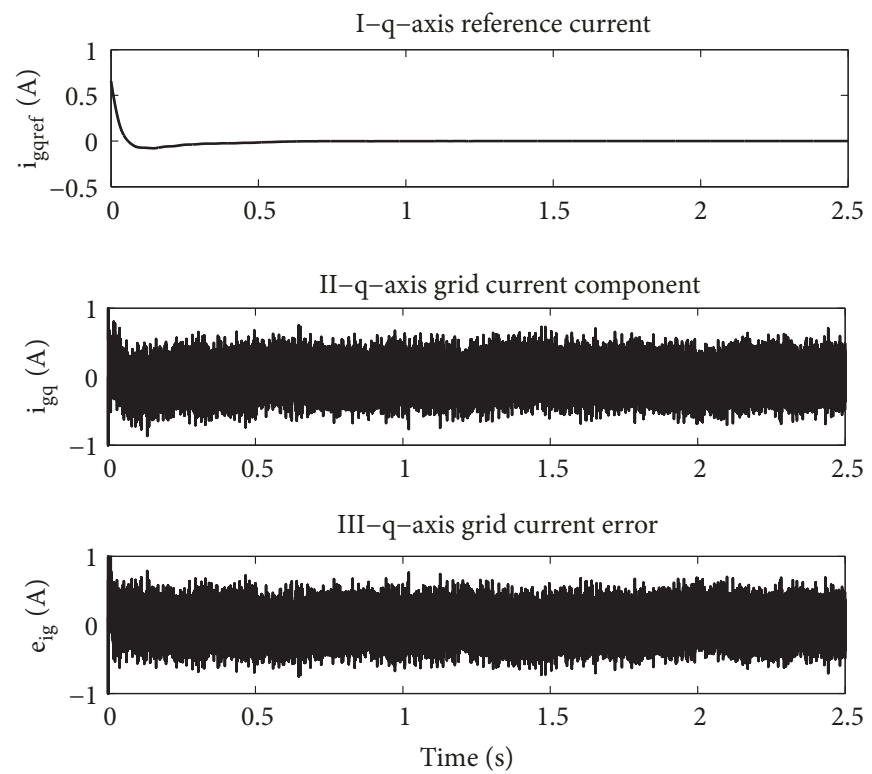

(b)

FIgURE 9: Performances of the grid side PI controllers in grid connected mode. (a) d-axis grid current reference (i), d-axis grid current component (ii), and d-axis grid current error (iii). (b) q-axis reference current (i), q-axis grid current component (ii), and q-axis grid current error (iii).

\section{Computing Results}

The effectiveness of the proposed control strategy has been tested by numerical simulations within the Matlab/Simulink software. Appendix A gives the parameters of the generator and rectifier. The control voltage base value and nonlinear relationship between mutual inductance and magnetizing current are also given in Appendix A. The variation of mutual inductance with magnetizing current for the induction machine under consideration is depicted in Figure 5.
In all simulations, the parameters of the rotor resistance estimator (69) have been chosen as $K=15.5$ and $K_{R_{r}}=110$. The equivalent injection terms have been approximated using a first-order low-pass filter with a time constant of $1 \mathrm{~ms}$.

The tuning parameters for the RBF neurosliding mode controllers used in the generator side have been chosen as follows: $\alpha_{\omega_{m}}=12000, \alpha_{v_{d c}}=14000, \alpha_{\phi_{r o t}}=5050, l_{\omega_{m}}=1.2$, $l_{v_{d c}}=0.75, l_{\phi_{\text {rot }}}=1.50, \varepsilon_{v_{d c}}=0.01, \varepsilon_{\phi_{\text {rot }}}=0.4, \varepsilon_{\omega_{m}}=0.1$, and $N=8$ for each neural controller.

The initial values of $\widehat{w}_{j}$ are random numbers. 

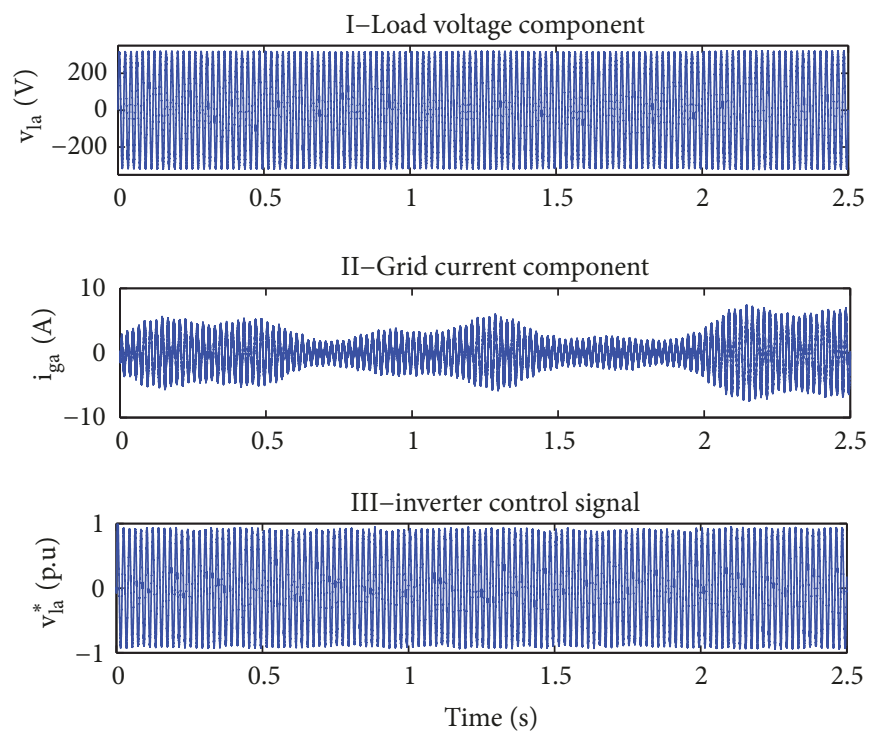

FIGURE 10: Performances of the grid side PI controllers in grid connected mode. Load phase voltage component (i), grid phase current component (ii), and inverter control signal (iii).

The turning parameters of the PI regulators in the inverter side have been chosen using the procedure described in Section 4 and the best results were obtained using the following gain values:

AC voltage regulator coefficients: $K_{P_{v d}}=2.5, K_{I_{v d}}=0.2$, $K_{P_{v q}}=1.6$, and $K_{I_{v q}}=0.07$.

Inverter current regulator coefficients: $K_{P_{i_{\text {invd }}}}=1.1$, $K_{I_{i_{\text {invd }}}}=0.15, K_{P_{i_{\text {invq }}}}=0.85$, and $K_{I_{i_{\text {invq }}}}=0.15$.

Grid current regulator coefficients: $K_{P_{i_{g d}}}=15, K_{I_{i_{g d}}}=$ $5000, K_{P_{i g q}}=25$, and $K_{I_{i g q}}=5000$.

During simulations, the resistive load $R$, capacitive load $R C$, and combined inductive-capacitive load $R L C$ were implemented at $t=0 s, t=1.5 s$, and $t=2 s$, respectively. The values of different loads were chosen as follows: resistive load R: $R=100 \Omega$; capacitive load $\mathrm{R} C: R=100 \Omega$ and $C=$ $30 \mu F$; combined inductive-capacitive load R L C: $R=100 \Omega$, $L=100 \mathrm{mH}$, and $\mathrm{C}=30 \mu \mathrm{F}$.

The parameters of the LCL filter used in the grid side inverter were selected using the procedure describe in [2] as $L_{1 f}=13.2 \mathrm{mH}, C_{f}=2.9 \mu \mathrm{F}$, and $L_{2 f}=3.15 \mathrm{mH}$.

All simulations have been conducted under noise conditions in the measured stator current with the magnitude of the noise reaching about $5 \%$ of the maximum value of the measurable stator current.

In the first set of simulations (Figures 7 and 8) the system operates in stand-alone mode. This test has been performed in order to verify the good performance of voltage controller.

In the second set of simulations (Figures 9 and 10) the system operates in grid connected mode. This test has been performed in order to demonstrate the good performance of the grid current controller; it equally presents the low-order harmonics in the grid current.

During the third set of simulations (Figures 11-14), the system started in grid connected mode and when the wind speed dropped below a certain preset value $(v=5 \mathrm{~m} / \mathrm{s})$, the power produced decreased and the system automatically switched from the grid to the three-phase AC load. The PWM inverter also switched automatically from current controlled to voltage controlled mode. When the wind speed exceeded the preset value, the PWM inverter switched back automatically to current controlled mode and the grid is reconnected again. This test has been performed to demonstrate the flexibility ability of the proposed control strategy.

Figure 6 presents the performances of the generator side RBF neurosliding controllers used in the three set of simulations.

In the fourth set of simulations (Figure 15) a constant wind profile is adopted. The PWM inverter is connected to the local load $\left(R_{L}\right)$. The system started in grid connected mode such that the excess power produce is transferred to the grid. At time $t=1 \mathrm{~s}$ the amount of power consumed by the local load is suddenly increased. This sudden change consists of varying the values of the main load resistance from $\left(R_{L}=100 \Omega\right)$ to the critical values $\left(R_{L}=35 \Omega\right)$. The PWM inverter switches automatically from current controlled to voltage controlled mode in order to satisfy the local load power requirement.

It can be seen from the simulations results that, on the generator side tracking errors for the DC bus voltage, generator rotor speed and rotor flux converge to zero in a very short and finite time under the influence of the proposed RBF-NSC controller. On the inverter side, very short settling time is required in the case of PI controller. It can be also noticed that the proposed controller provides better transient and steady state performances within a low wind speed range. Using the propose controllers configuration, it is possible to increase the energy production, especially, in the lows wind range, and it allows flexible switch between the stand-alone mode and grid connected mode. It is also noted that detection period is very short less than admitted limit, and it reduces the current rise. 

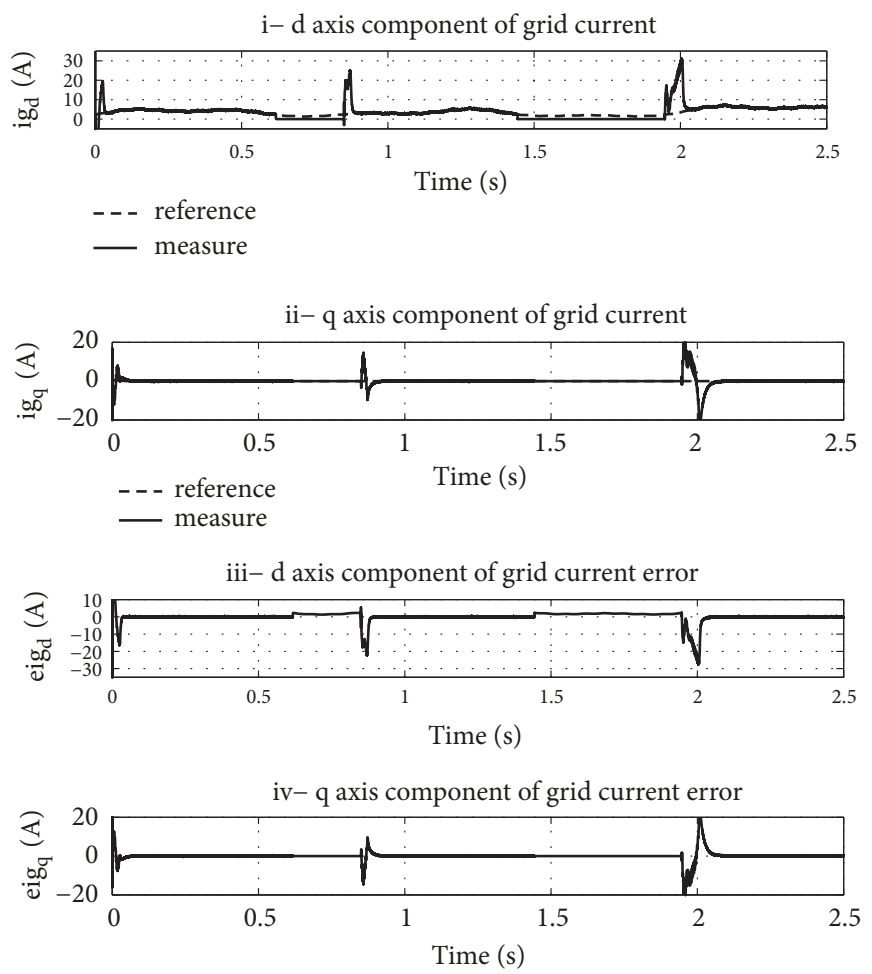

(a)
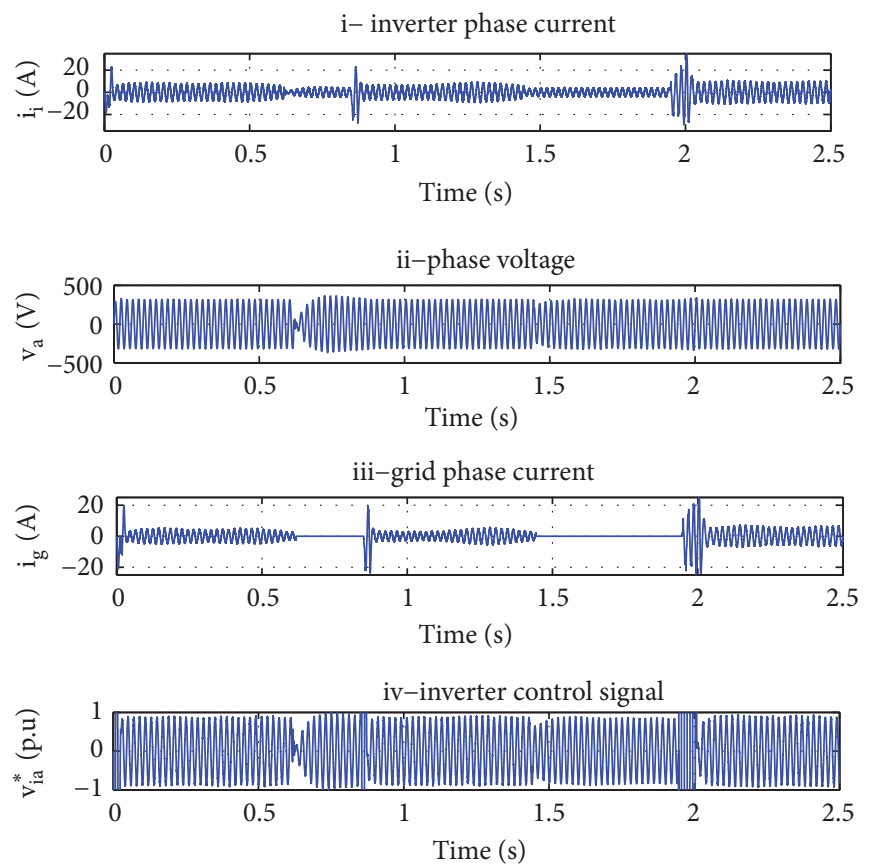

(b)

FIGURE 11: Performances of the grid side PI controllers in automatic switching mode. (a) d-axis grid current (i), q-axis grid current (ii), d-axis grid current error (iii), and q-axis grid current error (iv). (b) Inverter phase current (i), load phase voltage (ii), grid phase current (iii), and inverter control signal (iv). 

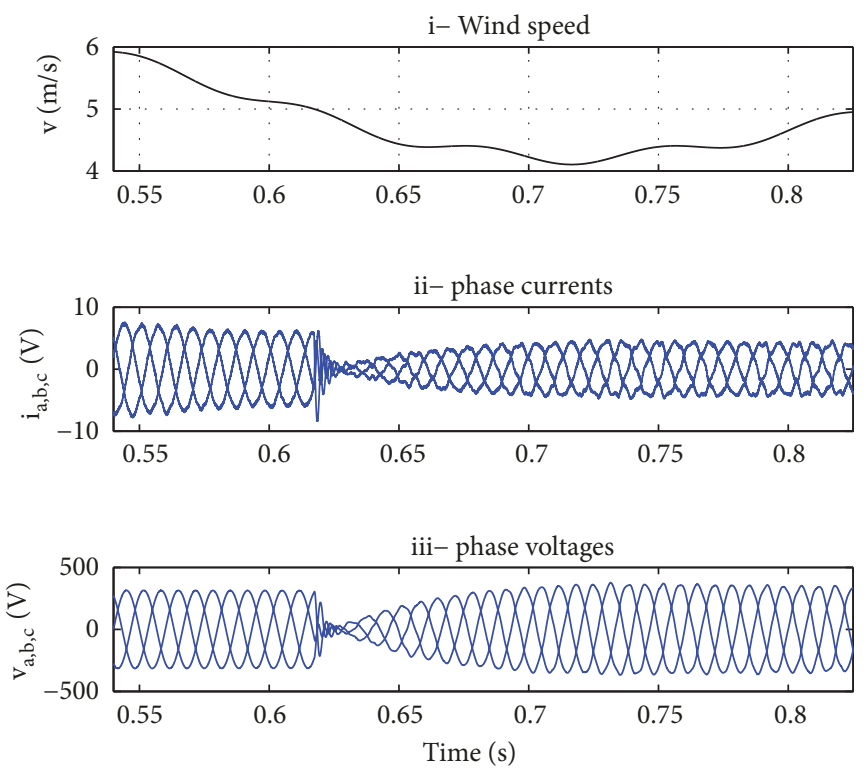

(a)
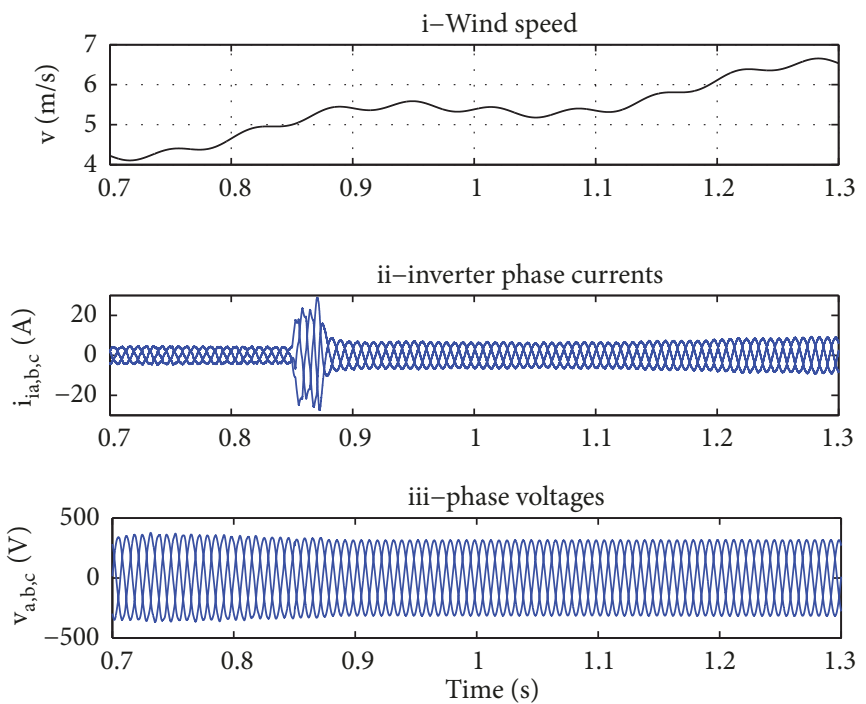

(b)

Figure 12: Performances of the proposed PI controllers in automatic switching mode. (a) Zoom on the transition from the grid connected mode to the stand-alone mode. (b) Zoom on the transition from the stand-alone mode to the grid connected mode.

\section{Conclusion}

A variable speed wind conversion system using a squirrelcage induction generator and two PWM converters has been presented in this paper. A new simple and robust control strategy has been proposed to transfer the maximum available power from the wind turbine to the utility grid through a controlled three-phase voltage source $(\mathrm{AC} / \mathrm{DC} / \mathrm{AC})$ converters. On the generator side of the system, the strategy consisted of regulating the rotor flux, the rotation speed of the induction generator, and the DC bus voltage using RBF neurosliding mode controllers associated with the rotor flux oriented vector control which takes into account the magnetization effect. On the grid side of the system, PI controllers are used to regulate the current and voltage of the inverter as well as the current injected into the network in the autonomous operation and grid connected modes respectively. The automatic switching between the two modes of operation depends on the wind speed which also determines the power produced. Grid synchronization is achieved using the PLL technique. The proposed scheme is robust and efficient and can be easily implemented in practice since finite time estimator for inaccessible parameters has been provided. Simulation results have shown that the proposed algorithm improves the dynamic performance of the global system studied. 

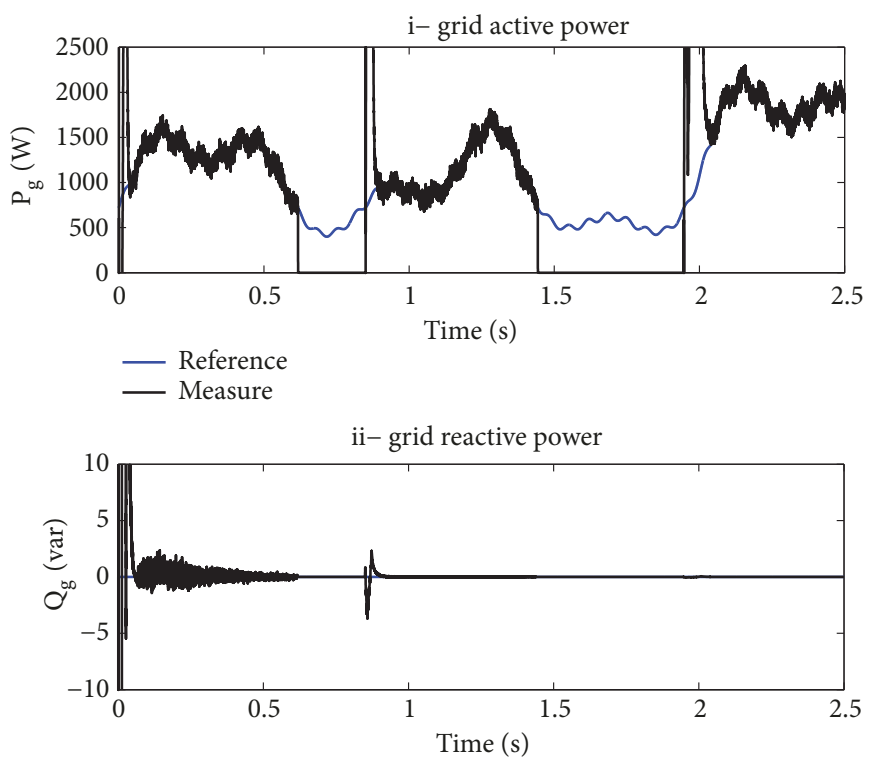

FIGURE 13: Active and reactive grid power in automatic switching mode.

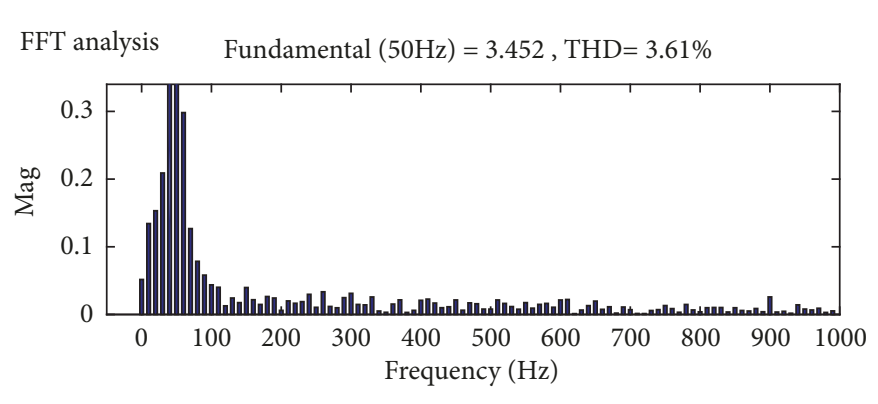

(a)

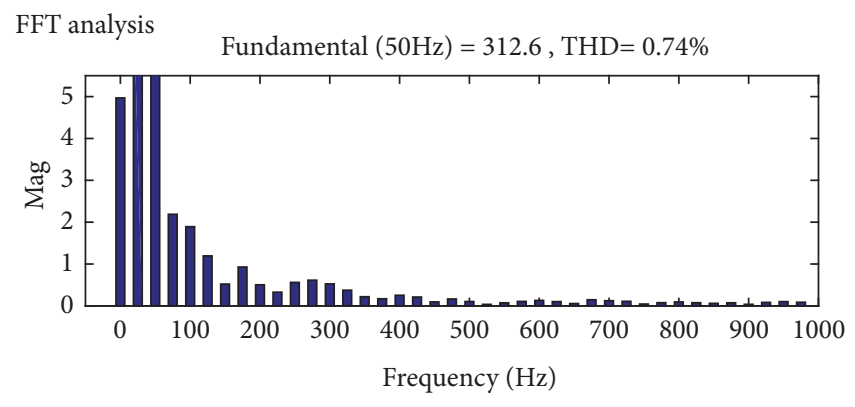

(b)

FIGURE 14: (a) Grid current harmonic spectra. (b) Voltage harmonic spectra.
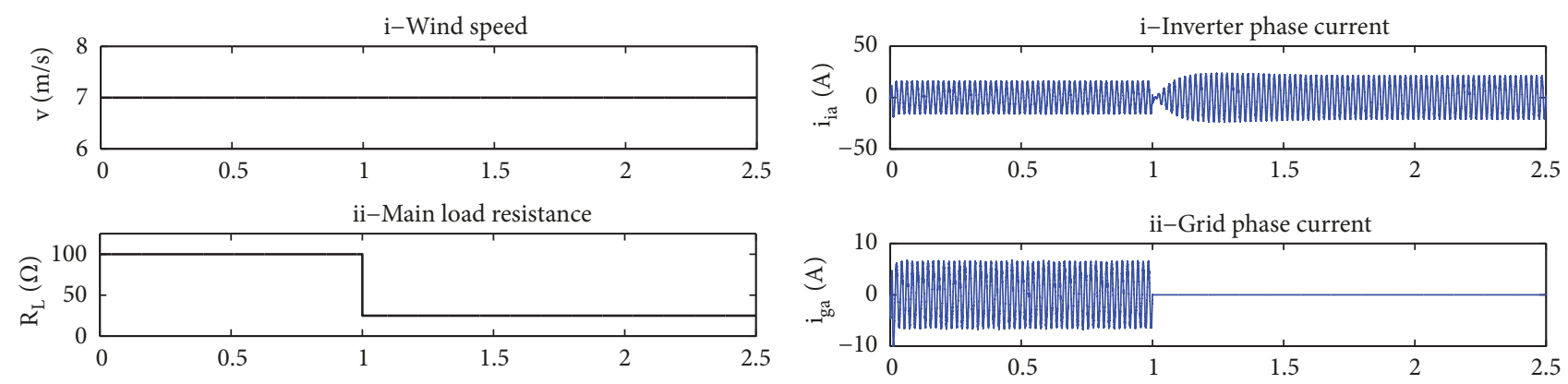

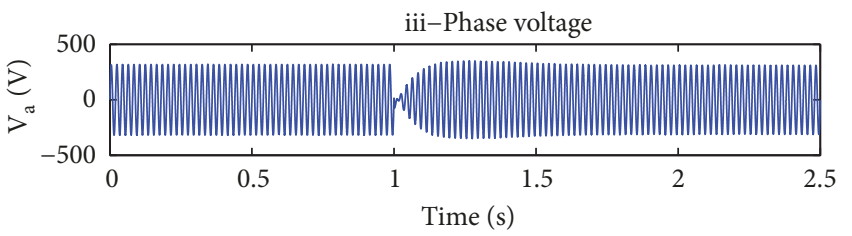

(a)

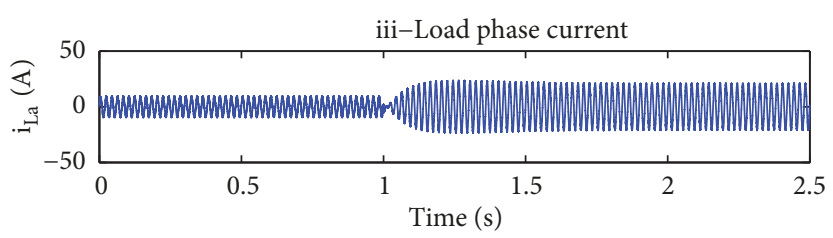

(b)

FIGURE 15: Performances of the grid side PI controllers in automatic switching mode. (a) Wind speed (i), main load resistance (ii), and load phase voltage (iii). (b) Inverter phase current (i), grid phase current (ii), and load phase current (iii). 


\section{Appendix}

\section{A.}

Parameters of the Induction Machine Used in the Simulation ([24]). Rated power: $3.5 \mathrm{~kW}$; phase-to-phase RMS nominal voltage: $415 \mathrm{~V}$; rated speed: $1450 \mathrm{rpm}$; rated field current: $7.8 \mathrm{~A} ; n_{p}=2 ; L_{r}=L_{s}=191.4 \mathrm{mH} ; L_{m}=180 \mathrm{mH}$; $R_{s}=1.66 \Omega ; R_{r}=2.75 \Omega$.

Nonlinear relationship between the mutual inductance and magnetizing current ([24]):

$$
\text { If } I_{m}<1.157
$$

Then $L_{m}=0.064 I_{m}^{4}-0.14 I_{m}^{3}+0.017 I_{m}^{2}+0.125 I_{m}$

$$
+0.23
$$

Else $L_{m}=3.98 \times 10^{-6} I_{m}^{4}-2.4 \times 10^{-4} I_{m}^{3}++5.48$

$$
\times 10^{-3} I_{m}^{2}-0.0605 I_{m}+0.3552 \text {. }
$$

Parameters of the Rectifier. Switching frequency: $10 \mathrm{kHz}$; DClink capacitor: $2000 \mu F$.

Base value of the control voltage: $415 \sqrt{2 / 3}$.

\section{B.}

Characteristics of Wind Turbine. Density of air $\rho=1.225$, areas swept by blade, $A=19.635 \mathrm{~m}^{2}$, optimum coefficient, $k_{\text {opt }}=0.0037 \mathrm{Nm} /(\mathrm{rad} / \mathrm{s})^{2}, C_{\text {pmax }}=0.48$, cut-in wind speed $v_{\min }=3.5 \mathrm{~m} / \mathrm{s}$, cut-out wind speed $v_{\max }=25 \mathrm{~m} / \mathrm{s}$, gearbox ratio $n_{g}=6.25$, turbine total inertia, $J_{t}=3 \mathrm{Kgm}^{2}$, and turbine total external damping, $f=0.0027 \mathrm{Nm} /(\mathrm{ras} / \mathrm{s})$

\section{C.}

Design of LCL Filter [2]. The AC filter acts to reduce higher harmonics distortion caused by power electronics devise switching process. The suitable calculation of LCL filter parameters is important to guarantee stable operation of grid connected converter.

\section{Base Values Setting}

$$
\begin{aligned}
& \text { Base impedance: } Z_{B}=U_{N}^{2} / P_{N} \\
& \text { Base inductance: } L_{B}=Z_{B} / \omega_{N} \\
& \text { Base capacitance: } C_{B}=1 / \omega_{N} Z_{B}
\end{aligned}
$$

where $\omega_{N}=\omega_{G}=2 * p i * 50$ is the nominal converter pulsation.

$U_{N}=U_{G}=220 * \sqrt{3}$ nominal phase-to-phase converter voltage nominal rms converter phase current can be computed as $I_{N}=P_{N} / \sqrt{3} U_{N}$.

Converter Side Inductance $L_{1 f}$ Calculation. The maximum ripple current $I_{\text {maxripref }}$ can be selected between $10 \%$ and $25 \%$ of nominal phase current $I_{N}$ assuming that $I_{\text {maxripref }}=$ $0.23 I_{N}$, converter side ripple current can be compute as
$I_{\text {maxrip }}=\sqrt{2} I_{\text {maxripref }} I_{N}$, and according to this the converter side inductance can be derived, where $f_{s w}$ is a switching frequency.

Filter Capacitance $C_{f}$ Calculation. The filter capacitance should be less than $5 \%$ of the base capacitance. Assuming that per unit capacitance is $C_{\text {fref }}=0.04 C_{B}$ the filter capacitance can be derived from

$$
\begin{aligned}
C_{f} & =C_{\text {fref }} C_{B}=C_{\text {fref }} \frac{1}{\omega_{N} Z_{B}}=C_{\text {fref }} \frac{P_{N}}{\omega_{N} U_{N}^{2}} \\
& =0.04 \frac{P_{N}}{\omega_{N} U_{N}^{2}}
\end{aligned}
$$

Grid Side Inductance $L_{2 f}$ Calculation. The grid side AC filter can be computed as

$$
L_{2 f}=r_{a} L_{1 f}
$$

where $r_{a}$ is a ratio between grid and converter side inductances. The factor can be calculated as $r_{a}=\mid(1-H A) / H A(1-$ $\left.L_{1 f} C_{f} \omega_{s w}^{2}\right) \mid$, where $H A$ is the harmonics attenuation of the phase currents for the switching frequency components. In this work $H A=0.075$ has been chosen

\section{Symbols}

$P_{\text {tur }}: \quad$ Aerodynamic power

$\rho: \quad$ Air density

$R: \quad$ Radius of the turbine

$v$ : Wind speed

$C_{p}: \quad$ Power coefficient

$\zeta: \quad$ Tip-speed ratio

$P^{*}: \quad$ Optimal turbine power

$\omega_{\text {mtur }}$ : $\quad$ Rotation speed of wind turbine

$J_{\text {tur }}: \quad$ Total moment of inertia for the rotor and dive-train

$\omega_{m}: \quad$ Generator rotor speed

$T_{\text {tur }}: \quad$ Aerodynamic torque

$e: \quad$ Tracking error

$T_{\text {em }}: \quad$ Electromagnetic torque

$f: \quad$ Turbine total external damping

$i_{s d}, i_{s q}: \quad$ Stator $\mathrm{d}$ and $\mathrm{q}$ winding currents

$R_{\text {rot }}: \quad$ Rotor per phase winding resistance

$R_{s}$ : $\quad$ Stator per phase winding resistance

$L_{\text {rot }}: \quad$ Rotor per phase winding inductance

$L_{s}$ : $\quad$ Stator per phase winding inductance

$L_{m}: \quad$ Mutual inductance

$C: \quad$ DC capacitance

$R: \quad$ Main load resistances

$R_{L}: \quad$ Dump load resistances

$v_{s d}, v_{s q}: \quad$ Stator $\mathrm{d}$ and $\mathrm{q}$ winding voltage

$\varphi_{\text {rotd }}, \varphi_{\text {rotq }}:$ Rotor $\mathrm{d}$ and $\mathrm{q}$ winding flux linkage

$n_{p}$ : $\quad$ Number of generator pole pairs

$\omega$ : $\quad$ Rotor pulsation

$i_{\text {inv }}: \quad$ Output inverter current

$v_{d c}: \quad$ DC bus voltage

$i_{\text {rot } \alpha}, i_{\text {rot } \beta}: \quad(\alpha$ and $\beta)$ Rotor currents components

$v_{s \alpha}, v_{s \beta}: \quad(\alpha$ and $\beta)$ Stator voltages components 
$S_{a}, S_{b}$ and $S_{c}$ : Rectifier voltage switching functions

$S_{d}, S_{q}: \quad \mathrm{d}$ and $\mathrm{q}$ switching functions of PWM technique

$v_{d}, v_{q}: \quad \mathrm{d}$ and $\mathrm{q}$ phase voltages at load terminals

$v_{\text {invd }}, v_{\text {invq }}: \mathrm{d}$ and q phase voltages at inverter output

$E_{g d}, E_{g q}: \quad \mathrm{d}$ and $q$ grid voltages

$i_{L d}, i_{L q}: \quad \mathrm{d}$ and $\mathrm{q}$ load currents

$i_{d g}, i_{q g}$ :

$L_{1 f}$ :

$L_{2 f}$ :

$C_{1 f}$ :

$(\alpha, \beta)$ :

d, $q$ :

$K_{P}$ :

$K_{I}$ :

$\widehat{x}:$

$P_{g}, Q_{g}$ :

LCL filter inductor in inverter side

LCL filter inductor in grid side

LCL filter capacitor

Stationary $\alpha-\beta$ axis

Synchronous $d-q$ axis

Proportional gain of controller

Integrate gain of controller

Estimation of $\mathrm{x}$

Grid side converter output active and
Grid side converter $\mathrm{d}$ and q output current

reactive power.

\section{Data Availability}

The data used to support the findings of this study are available from the corresponding author upon request.

\section{Conflicts of Interest}

The authors declare that they have no conflicts of interest.

\section{References}

[1] S. A. Deraz and F. E. Abdel Kader, "A new control strategy for a stand-alone self-excited induction generator driven by a variable speed wind turbine," Journal of Renewable Energy, vol. 51, pp. 263-273, 2013.

[2] M. P. Kazmierkowski, R. Krishman, and F. Blaabjerg, "Control in power electronics," in Selected Problems, pp. 454-465, Academic, New York, NY, USA, 2002.

[3] T. Rohit and N. Moham, "Seamless transfert of a grid-connected PWM inverters betwen utility-interactive and stand alone modes," in Proceedings of the APEC'02 Conference, vol. 2, pp. 1081-1086, 2002.

[4] V. Urundady and P. K. Vittal, "Power control strategy for grid connected permanent magnet synchronous generator of a distributed generation unit," International Journal of Power and Energy Conversion, vol. 5, no. 3, pp. 274-297, 2014.

[5] G. Kenne, R. M. Douanla, and F. B. Pelap, "An adaptive nonlinear Control Strategy for a stand-alone permanent synchronous Generator Driven by a variable Speed Wind Turbine," International Journal of Dynamics and Control, vol. 5, no. 4, pp. 1103-1113, 2017.

[6] G. Kenne, C. T. Sanjong, and E. M. Nfah, "Adaptive PI control strategy for a self-excited induction generator driven by a variable speed wind turbine," Journal of Circuits, Systems and Computers, vol. 26, no. 2, 2017.

[7] E. Twining and D. G. Holmes, "Grid current regulation of a three-phase voltage source inverter with an LCL input filter," IEEE Transactions on Power Electronics, vol. 18, no. 3, pp. 888$895,2003$.
[8] R. Teodorescu and F. Blaabjerg, "Flexible control of small wind turbines with grid failure detection operating in standalone and grid-connected mode," IEEE Transactions on Power Electronics, vol. 19, no. 5, pp. 1323-1332, 2004.

[9] G. Mehta and S. P. Singh, "Design of single-stage three-phase grid-connected photovoltaic system with MPPT and reactive power compensation control," International Journal of Power and Energy Conversion, vol. 5, no. 3, pp. 211-227, 2014.

[10] G. Kenné, A. S. Fotso, and F. Lamnabhi-Lagarrigue, "A new adaptive control strategy for a class of nonlinear system using RBF neuro-sliding-mode technique: application to SEIG wind turbine control system," International Journal of Control, vol. 90 , no. 4, pp. 855-872, 2017.

[11] G. Kenné, T. C. Sanjong, S. A. Fotso, and N. E. Mbaka, "A robust control strategy for self-excited induction generator wind turbine system," International Journal of Dynamics and Control, 2016.

[12] F. M. E. Fayez, O. Mohamed, and G. Hatem, "Maximun power point tracking control scheme for grid connected variable speed wind driven self-excited induction generator," Journal of power Electronics, vol. 6, no. 1, pp. 52-66, 2006 (Chinese).

[13] D. S. Yoo and M. J. Chung, "A variable structure control with simple adaptation laws for upper bounds on the norm of the uncertainties," IEEE Transactions on Automatic Control, vol. 37, no. 6, pp. 860-865, 1992.

[14] Y.-S. Lu and J.-S. Chen, "Design of a perturbation estimator using the theory of variable-structure systems and its application to magnetic levitation systems," IEEE Transactions on Industrial Electronics, vol. 42, no. 3, pp. 281-289, 1995.

[15] R. Marino and P. Tomei, Nonlinear Adaptive Design: Geometric, Adaptive, and Robust, Prentice-Hall International (UK)Limited, London, UK, 1995.

[16] S. S. Ge, C. C. Hang, and T. Zhang, "A direct method for robust adaptive nonlinear control with guaranteed transient performance," Systems \& Control Letters, vol. 37, no. 5, pp. 275284, 1999.

[17] S. Chen, S. A. Billings, C. F. Cowan, and P. M. Grant, "Practical identification of narmax models using radial basis functions," International Journal of Control, vol. 52, no. 5, pp. 1327-1350, 1990.

[18] S. Chen and S. A. Billings, "Neural networks for nonlinear dynamic system modelling and identification," International Journal of Control, vol. 56, no. 2, pp. 319-346, 1992.

[19] T. Ahmed-Ali, G. Kenné, and F. Lamnabhi-Lagarrigue, "Identification of nonlinear systems with time-varying parameters using a sliding-neural network observer," Neurocomputing, vol. 72, no. 7-9, pp. 1611-1620, 2009.

[20] D. G. Luenberger, Linear and Nonlinear Programming, AddisonWesley Publishing Compagny, Boston, Mass, USA, 1984.

[21] F. Jaramillo-Lopez, G. Kenne, and F. Lamnabhi-Lagarrigue, "A novel online training neural network-based algorithm for wind speed estimation and adaptive control of PMSG wind turbine system for maximum power extraction," Journal of Renewable Energy, vol. 86, pp. 38-48, 2016.

[22] B. Beltran, T. Ahmed-Ali, and M. E. H. Benbouzid, "High-order sliding-mode control of variable-speed wind turbines," IEEE Transactions on Industrial Electronics, vol. 56, no. 9, pp. 33143321, 2009.

[23] M. E. Haque, M. Negnevitsky, and K. M. Muttaqi, "A novel control strategy for a variable speed wind turbine with a permanent magnet synchronous generator," in Proceedings of 
the 2008 IEEE Industry Applications Society Annual Meeting, IAS'08, pp. 1-8, Canada, October 2008.

[24] D. Seyoum, C. Grantham, and M. F. Rahman, "Inverter supplied voltage control system for an isolated induction generator driven by a wind turbine," in Proceedings of the 2003 IEEE Industry Applications Conference; 38th IAS Annual Meeting: Crossroads To Innovation, vol. 1, pp. 568-575, USA, October 2003.

[25] G. Kenné, R. S. Simo, F. Lamnabhi-Lagarrigue, A. Arzandé, and J. C. Vannier, "An online simplified rotor resistance estimator for induction motors," IEEE Transactions on Control Systems Technology, vol. 18, no. 5, pp. 1188-1194, 2010.

[26] W. Leonhard, Control of Electric Drives, Springer, 2003.

[27] R. Marino, S. Peresada, and P. Tomei, "On-line stator and rotor resistance estimation for induction motors," IEEE Transactions on Control Systems Technology, vol. 8, no. 3, pp. 570-579, 2000. 


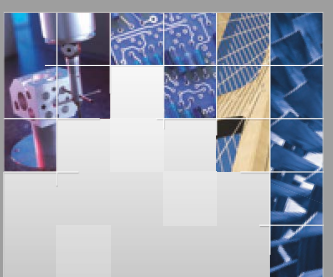

\section{Enfincering}
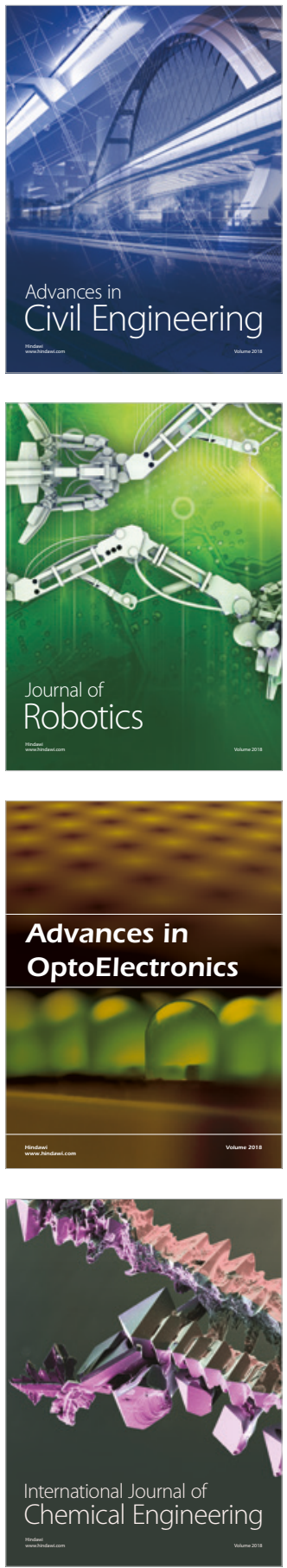

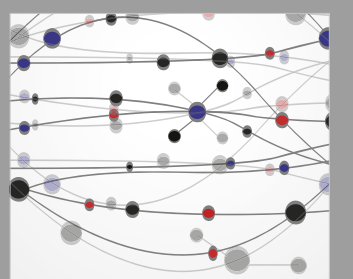

\section{Rotating \\ Machinery}

The Scientific World Journal

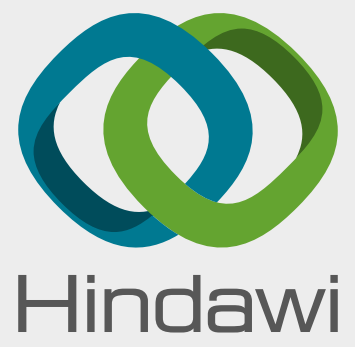

Submit your manuscripts at

www.hindawi.com
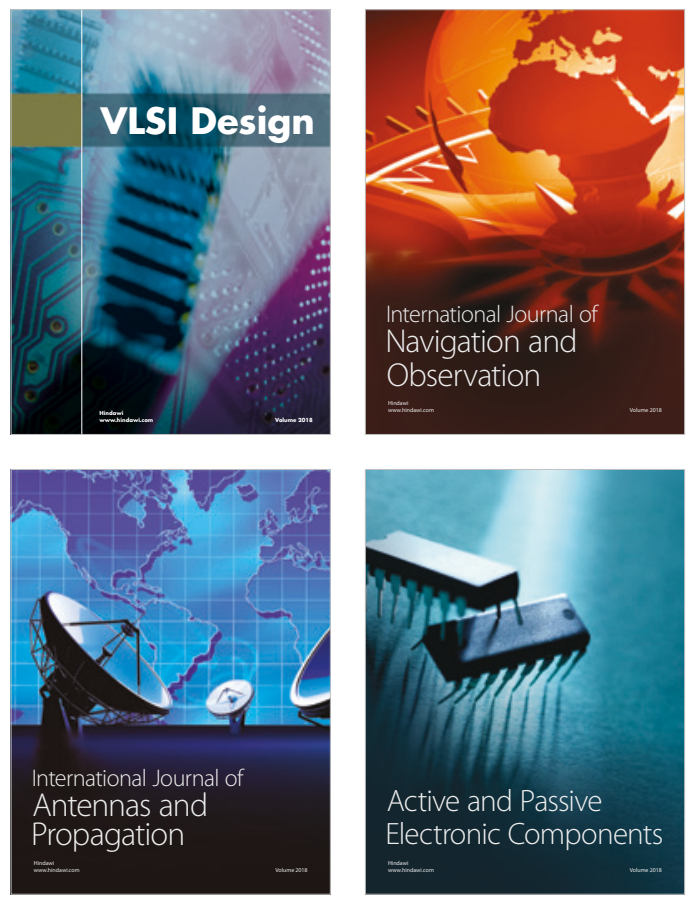
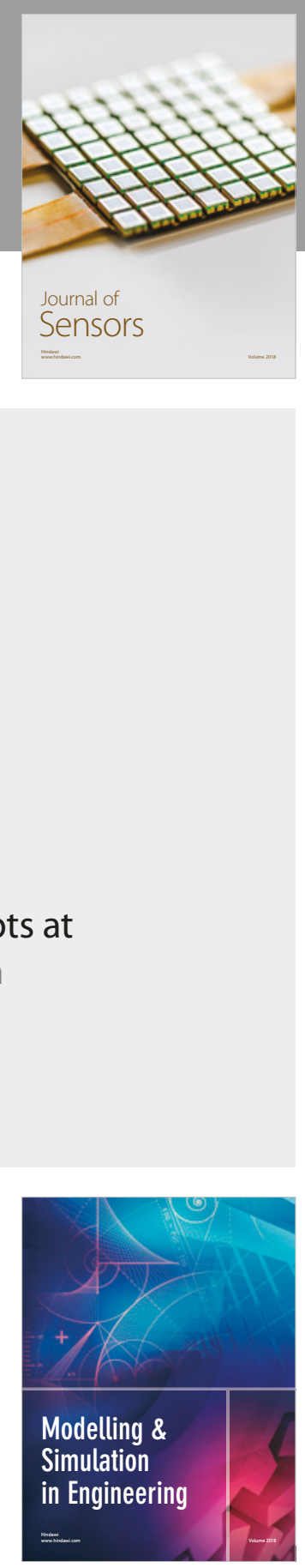

\section{Advances \\ Multimedia}
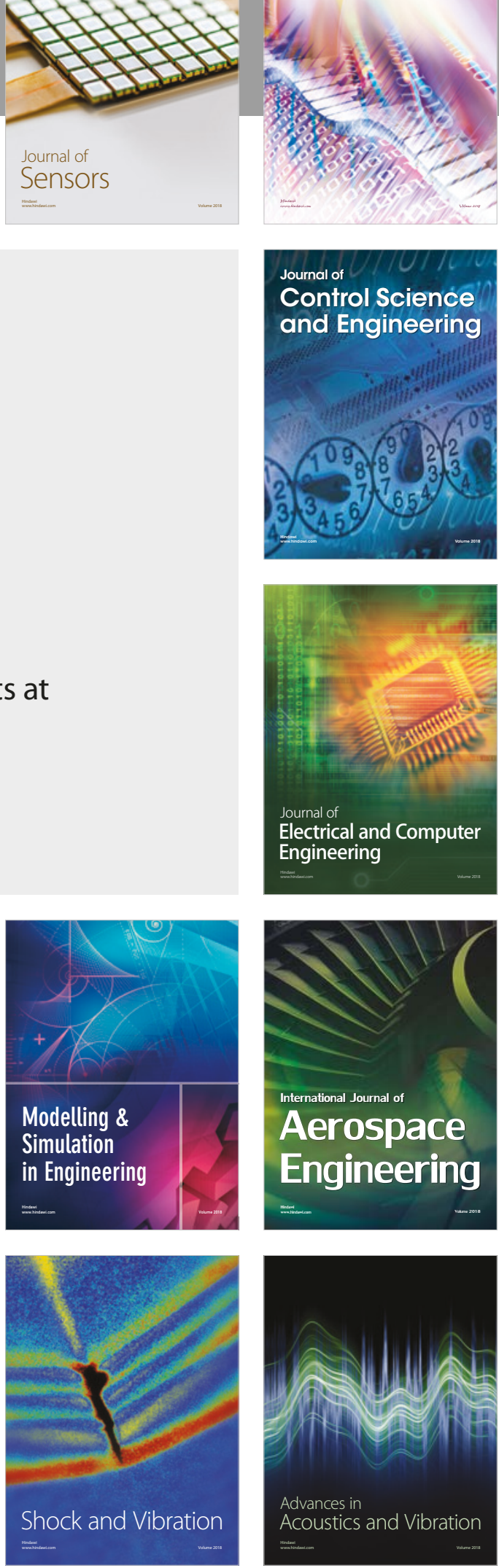